\title{
Do surface lateral flows matter for data assimilation of soil moisture observations into hyperresolution land models?
}

\author{
Yohei Sawada ${ }^{1,2}$ \\ ${ }^{1}$ Institute of Engineering Innovation, the University of Tokyo, Tokyo, Japan \\ ${ }^{2}$ Meteorological Research Institute, Japan Meteorological Agency, Tsukuba, Japan \\ Correspondence: Yohei Sawada (yohei.sawada@sogo.t.u-tokyo.ac.jp)
}

Received: 3 March 2020 - Discussion started: 30 March 2020

Revised: 29 June 2020 - Accepted: 4 July 2020 - Published: 4 August 2020

\begin{abstract}
It is expected that hyperresolution land modeling substantially innovates the simulation of terrestrial water, energy, and carbon cycles. The major advantage of hyperresolution land models against conventional 1-D land surface models is that hyperresolution land models can explicitly simulate lateral water flows. Despite many efforts on data assimilation of hydrological observations into those hyperresolution land models, how surface water flows driven by local topography matter for data assimilation of soil moisture observations has not been fully clarified. Here I perform two minimalist synthetic experiments where soil moisture observations are assimilated into an integrated surface-groundwater land model by an ensemble Kalman filter. I discuss how differently the ensemble Kalman filter works when surface lateral flows are switched on and off. A horizontal background error covariance provided by overland flows is important for adjusting the unobserved state variables (pressure head and soil moisture) and parameters (saturated hydraulic conductivity). However, the non-Gaussianity of the background error provided by the nonlinearity of a topography-driven surface flow harms the performance of data assimilation. It is difficult to efficiently constrain model states at the edge of the area where the topography-driven surface flow reaches by linear-Gaussian filters. It brings the new challenge in land data assimilation for hyperresolution land models. This study highlights the importance of surface lateral flows in hydrological data assimilation.
\end{abstract}

\section{Introduction}

Hyperresolution land modeling is expected to improve the simulation of terrestrial water, energy, and carbon cycles, which is crucially important for meteorological, hydrological, and ecological applications (see Wood et al., 2011, for a comprehensive review). While conventional land surface models (LSMs) assume that lateral water flows are negligible at the coarse resolution ( $>25 \mathrm{~km}$ ) and solve the vertical 1-D Richards equation for the soil moisture simulation (e.g., Sellers et al., 1996; Lawrence et al., 2011), currently proposed hyperresolution land models, which can be applied at a finer resolution $(<1 \mathrm{~km})$, explicitly consider surface and subsurface lateral water flows (e.g., Maxwell and Miller, 2005; Tian et al., 2012; Shrestha et al., 2014; Niu et al., 2014). The fine horizontal resolution can resolve slopes, which are drivers of a lateral transport of water, and realize the fully integrated surface-groundwater modeling. Previous works indicated that a lateral transport of water strongly controls latent heat flux and the partitioning of evapotranspiration into base soil evaporation and plant transpiration (e.g., Maxwell and Condon, 2016; Ji et al., 2017; Fang et al., 2017). This effect of a lateral transport of water on land-atmosphere interactions has been recognized (e.g., Williams and Maxwell, 2011; Keune et al., 2016).

Data assimilation has contributed to improving the performance of LSMs by fusing simulation and observation. The grand challenge of land data assimilation is to improve the simulation of unobservable variables using observations by propagating an observation's information into a model's high-dimensional state and parameter space. In previous works on the conventional 1-D LSMs, many land data 
assimilation systems (LDASs) have been proposed to accurately estimate a model's state and parameter variables, which cannot be directly observed, by assimilating satellite and in situ observations. For example, the optimization of an LSM's unknown parameters (e.g., hydraulic conductivity) has been implemented by assimilating remotely sensed microwave observations (e.g., Yang et al., 2007, 2009; Bandara et al., 2014, 2015; Sawada and Koike, 2014; Han et al., 2014). Kumar et al. (2009) focused on the correlation between surface and root-zone soil moisture to examine the potential of assimilating surface soil moisture observations to estimate root-zone soil moisture. Sawada et al. (2015) successfully improved the simulation of root-zone soil moisture by assimilating microwave brightness temperature observations which include the information of vegetation water content. Gravity Recovery and Climate Experiment total water storage observation has been intensively used to improve the simulation of groundwater and soil moisture (e.g., Li et al., 2012; Houborg et al., 2012). Improving the simulation of state variables such as soil moisture and biomass by LDASs has contributed to accurately estimating fluxes such as evapotranspiration (e.g., Martens et al., 2017) and $\mathrm{CO}_{2}$ flux (e.g., Verbeeck et al., 2011). However, in most of the studies on the conventional 1-D LDASs, observations impacted state variables and parameters only in a single model's horizontal grid which is identical to the location of the observation. The assumption that the water flows are restricted to the vertical direction in LSMs makes it difficult to propagate an observation's information horizontally. It limits the potential of land data assimilation to fully use land hydrological observations.

The hyperresolution land models, which explicitly solve surface and subsurface lateral flows, provide a unique opportunity to examine the potential of land data assimilation to propagate an observation's information horizontally in a model space and efficiently use land hydrological observations. Previous works successfully applied ensemble Kalman filters (EnKFs) to 3-D Richards' equation-based integrated surface-groundwater models. For example, Camporese et al. $(2009,2010)$ successfully assimilated synthetic observations of surface pressure head and streamflow into the Catchment Hydrology (CATHY). Ridler et al. (2014) successfully assimilated Soil Moisture and Ocean Salinity satellite-observed surface soil moisture into the MIKE SHE distributed hydrological model (see also Zhang et al., 2015). Kurtz et al. (2016) coupled the Parallel Data Assimilation Framework (PDAF) (Nerger and Hiller, 2013) with the Terrestrial System Modelling Framework (TerrSysMP) (Shrestha et al., 2014) and successfully estimated the spatial distribution of soil moisture and saturated hydraulic conductivity in the synthetic experiment (see also Zhang et al., 2018). In addition, Kurtz et al. (2016) indicated that their EnKF approach is computationally efficient in highperformance computers. Those studies have significantly contributed to fully assimilating the new high-resolution soil moisture observations such as Sentinel-1 (e.g., Paroscia et al., 2013).

Although the data assimilation of hydrological observations into hyperresolution land models has been successfully implemented in the synthetic experiments, it is unclear how topography-driven surface lateral water flows matter for data assimilation of soil moisture observations. Previous studies on data assimilation with high-resolution models mainly focused on assimilating groundwater observations (e.g., AitEl-Fquih et al., 2016; Rasmussen et al., 2015; HendricksFranssen et al., 2008). There are some applications which focused on the observation of soil moisture and pressure head in shallow unsaturated soil layers. However, in those studies, topography-driven surface flow was not considered in the experiment (Kurtz et al., 2016) or the role of them in assimilating observations into the hyperresolution land models was not quantitatively discussed (Camporese et al., 2009, 2010). This study aims at clarifying whether surface lateral flows matter for data assimilation of soil moisture observations into hyperresolution land models by a minimalist numerical experiment.

\section{Methods}

\subsection{Model}

ParFlow is an open-source platform which realizes fully integrated surface-groundwater flow modeling (Kollet and Maxwell, 2006; Maxwell et al., 2015). This model can be efficiently parallelized in high-performance computers and has been widely used as a core hydrological module in hyperresolution land models (e.g., Maxwell and Kollet, 2008; Maxwell and Condon, 2016; Fang et al., 2017; Kurtz et al., 2016; Maxwell et al., 2011; Williams and Maxwell, 2011; Shrestha et al., 2014). Since I used this widely adopted solver as is and added nothing new to the model physics, I described the method of ParFlow to simulate integrated surface-subsurface water flows briefly and omitted the details of numerical methods. The complete description of ParFlow can be found in Kollet and Maxwell (2006) and Maxwell et al. (2015) and references therein.

In the subsurface, ParFlow solves the variably saturated Richards equation in three dimensions.

$$
\begin{aligned}
& S_{\mathrm{S}} S_{\mathrm{W}}(h) \frac{\partial h}{\partial t}+\phi S_{\mathrm{W}}(h) \frac{\partial S_{\mathrm{W}}(h)}{\partial t}=\nabla \cdot q+q_{\mathrm{r}} \\
& q=-\mathbf{K}_{\mathrm{s}}(\boldsymbol{x}) k_{\mathrm{r}}(h)\left[\nabla(h+z) \cos \theta_{x}+\sin \theta_{x}\right]
\end{aligned}
$$

In Eq. (1), $h$ is the pressure head (L); $z$ is the elevation with the $z$ axis specified as upward (L); $S_{\mathrm{S}}$ is the specific storage $\left(\mathrm{L}^{-1}\right) ; S_{\mathrm{W}}$ is the relative saturation; $\phi$ is the porosity (); $q_{\mathrm{r}}$ is a source/sink term. Equation (2) describes the flux $q\left(\mathrm{~L} \mathrm{~T}^{-1}\right)$ by Darcy's law, and $\mathbf{K}_{\mathrm{s}}$ is the saturated hydraulic conductivity tensor $\left(\mathrm{L} \mathrm{T}^{-1}\right) ; k_{\mathrm{r}}$ is the relative permeability (); $\theta$ is the local angle of the topographic slope (see Maxwell 
et al., 2015). In this paper, the saturated hydraulic conductivity is assumed to be isotropic and a function of $z$ :

$\mathbf{K}_{\mathrm{s}}=K_{\mathrm{s}}(z)=K_{\mathrm{s}, \text { surface }} \exp \left(-f\left(z_{\text {surface }}-z\right)\right)$,

where $K_{\mathrm{s} \text { surface }}$ is the saturated hydraulic conductivity at the surface soil, and $z_{\text {surface }}$ is the elevation of the soil surface. The saturated hydraulic conductivity decreases exponentially as the soil depth increases (Beven, 1982). A van Genuchten relationship (van Genuchten, 1980) is used for the relative saturation and permeability functions.

$$
\begin{aligned}
& S_{\mathrm{W}}(h)=\frac{S_{\mathrm{sat}}-S_{\mathrm{res}}}{\left(1+(\alpha h)^{n}\right)^{\left(1-\frac{1}{n}\right)}}+S_{\mathrm{res}}, \\
& k_{\mathrm{r}}(h)=\frac{\left(1-\frac{(\alpha h)^{n-1}}{\left(1+(\alpha h)^{n}\right)^{\left(1-\frac{1}{n}\right)}}\right)^{2}}{\left(1+(\alpha h)^{n}\right)^{\frac{\left(1-\frac{1}{n}\right)}{2}}},
\end{aligned}
$$

where $\alpha\left(\mathrm{L}^{-1}\right)$ and $n(-)$ are soil parameters, $S_{\text {sat }}$ is the relative saturated water content, and $S_{\text {res }}$ is the relative residual saturation.

Overland flow is solved by the 2-D kinematic wave equation. The dynamics of the surface ponding depth, $h(\mathrm{~L})$, can be described by

$\boldsymbol{k} \cdot\left[-K_{\mathrm{S}}(z) k_{\mathrm{r}}(h) \cdot \nabla(h+z)\right]=\frac{\partial\|h, 0\|}{\partial t}-\nabla \cdot\|h, 0\| \boldsymbol{v}_{\mathrm{sW}}+q_{\mathrm{r}}$.

In Eq. (6), $\boldsymbol{k}$ is the unit vector in the vertical and $\|h, 0\|$ indicates the greater value of the two quantities following the notation of Maxwell et al. (2015). This formulation results in the overland flow equation being represented as a boundary condition to the variably saturated Richards equation (Kollet and Maxwell, 2006). If $h<0$, Eq. (6) describes vertical fluxes across the land surface as equal to the source/sink term $q_{\mathrm{r}}$ (i.e., rainfall and evapotranspiration). If $h>0$, the terms on the right-hand side of Eq. (6), which indicate water fluxes routed according to surface topography, are active. $\boldsymbol{v}_{\mathrm{sw}}$ is the 2-D depth-averaged water flow velocity $\left(\mathrm{L} \mathrm{T}^{-1}\right)$ and is estimated by Manning's law:

$\boldsymbol{v}_{\mathrm{sw}, x}=\left(\frac{\sqrt{S_{\mathrm{f}, x}}}{n_{\mathrm{M}}} h^{\frac{2}{3}}\right), \boldsymbol{v}_{\mathrm{sw}, y}=\left(\frac{\sqrt{S_{\mathrm{f}, y}}}{n_{\mathrm{M}}} h^{\frac{2}{3}}\right)$,

where $S_{\mathrm{f}, x}$ and $S_{\mathrm{f}, y}$ are the friction slopes (-) for the $x$ and $y$ directions, respectively; $n_{\mathrm{M}}$ is the Manning coefficient $\left(\mathrm{TL}^{-1 / 3}\right)$. In the kinematic wave approximation, the friction slopes are set to the bed slopes. The methodology of discretization and the numerical method to solve Eqs. (1)-(7) can be found in Kollet and Maxwell (2006).

\subsection{Data assimilation}

In this paper, the EnKF was applied to assimilate soil moisture observations into ParFlow. The EnKF has widely been applied to hyperresolution land models (e.g., Camporese et al., 2009, 2010; Ridler et al., 2014; Zhang et al., 2015, 2018; Kurtz et al., 2016). I examined whether surface lateral flows matter for data assimilation of soil moisture observations into hyperresolution land models using this widely adopted data assimilation method.

The Parflow model can be formulated as a discrete statespace dynamic system:

$\boldsymbol{x}(t+1)=f(\boldsymbol{x}(t), \boldsymbol{\theta}, \boldsymbol{u}(t))+\boldsymbol{q}(t)$,

where $\boldsymbol{x}(t)$ is the state variable (i.e., pressure head), $\boldsymbol{\theta}$ is the time-invariant model parameter (i.e., saturated hydraulic conductivity), $\boldsymbol{u}(t)$ is the external forcing (i.e., rainfall and evapotranspiration), and $\boldsymbol{q}(t)$ is the noise process which represents the model error. In data assimilation, it is useful to formulate an observation process as follows:

$\boldsymbol{y}^{\mathrm{f}}(t)=H(\boldsymbol{x}(t))+\boldsymbol{r}(t)$,

where $\boldsymbol{y}^{\mathrm{f}}(t)$ is the simulated observation, $H$ is the observation operator which maps the model's state variables into the observable variables, and $\boldsymbol{r}(t)$ is the noise process which represents the observation error. The purpose of EnKF (and any other data assimilation methods) is to find the optimal state variables $\boldsymbol{x}(t)$ based on the simulation $\boldsymbol{y}^{\mathrm{f}}(t)$ and observation (defined as $\left.\boldsymbol{y}^{0}\right)$ considering their errors $(\boldsymbol{q}(t)$ and $\boldsymbol{r}(t)$ ).

The general description of the Kalman filter is the following:

$$
\begin{aligned}
& \boldsymbol{x}^{\mathrm{f}}(t)=M\left[\boldsymbol{x}^{\mathrm{a}}(t-1)\right], \\
& \boldsymbol{x}^{\mathrm{a}}(t)=\boldsymbol{x}^{f}(t)+\mathbf{K}\left[\boldsymbol{y}^{\mathrm{o}}-H\left(\boldsymbol{x}^{\mathrm{f}}(t)\right)\right], \\
& \mathbf{K}=\mathbf{P}^{\mathrm{f}} \mathbf{H}^{\mathrm{T}}\left(\mathbf{H} \mathbf{P}^{\mathrm{f}} \mathbf{H}^{\mathrm{T}}+\mathbf{R}\right)^{-1}, \\
& \mathbf{P}^{\mathrm{a}}=(\mathbf{I}-\mathbf{K} \mathbf{H}) \mathbf{P}^{\mathrm{f}} .
\end{aligned}
$$

I follow the notation of Houtekamer and Zhang (2016). Superscripts $\mathrm{f}$ and a are forecast and analysis, respectively. In Eq. (10), a forecast model $M$ (ParFlow in this study) is used to obtain a prior estimate at time $t, \boldsymbol{x}^{\mathrm{f}}(t)$, from the estimation at the previous time $x^{\mathrm{a}}(t-1)$. In Eq. (11), a prior estimate $\boldsymbol{x}^{\mathrm{f}}(t)$ is updated to the analysis state, $\boldsymbol{x}^{\mathrm{a}}(t)$, using new observations $\boldsymbol{y}^{\mathrm{o}}$. The Kalman gain matrix $\mathbf{K}$, calculated by Eq. (12), gives an appropriate weight for the observations with an error covariance matrix $\mathbf{R}$ and the prior with an error covariance matrix $\mathbf{P}^{\mathrm{f}}$. $\mathbf{P}^{\mathrm{a}}$ is an updated analysis error covariance. To calculate $\mathbf{K}$, the observation operator $\mathbf{H}$ is needed to map from model space to observation space. It should be noted that Eqs. (10)-(13) give an optimal estimation only when the model and observation errors follow the Gaussian distribution. When the probabilistic distribution of the error in either model or observation has a non-Gaussian structure, results of the Kalman filter are suboptimal. This point is important for interpreting the results of this study. 
EnKF is the Monte Carlo implementation of Eqs. (10)(13). To compute the Kalman gain matrix, $\mathbf{K}$, ensemble approximations of $\mathbf{P}^{\mathrm{f}} \mathbf{H}^{\mathrm{T}}$ and $\mathbf{H} \mathbf{P}^{\mathrm{f}} \mathbf{H}^{\mathrm{T}}$ can be given by

$\mathbf{P}^{\mathrm{f}} \mathbf{H}^{\mathrm{T}} \equiv \frac{1}{k-1} \sum_{i=1}^{k}\left(\boldsymbol{x}_{i}^{\mathrm{f}}-\overline{\boldsymbol{x}^{\mathrm{f}}}\right)\left(H \boldsymbol{x}_{i}^{\mathrm{f}}-\overline{H \boldsymbol{x}^{\mathrm{f}}}\right)^{T}$

$\mathbf{H} \mathbf{P}^{\mathrm{f}} \mathbf{H}^{\mathrm{T}} \equiv \frac{1}{k-1} \sum_{i=1}^{k}\left(H \boldsymbol{x}_{i}^{\mathrm{f}}-\overline{H \boldsymbol{x}^{\mathrm{f}}}\right)\left(H \boldsymbol{x}_{i}^{\mathrm{f}}-\overline{H \boldsymbol{x}^{\mathrm{f}}}\right)^{T}$,

where $\boldsymbol{x}_{i}^{\mathrm{f}}$ is the $i$ th member of a $k$-member ensemble prior and $\overline{\boldsymbol{x}^{\mathrm{f}}}=\frac{1}{k} \sum_{i=1}^{k} \boldsymbol{x}_{i}^{\mathrm{f}}$ and $\overline{H \boldsymbol{x}^{\mathrm{f}}}=\frac{1}{k} \sum_{i=1}^{k} H \boldsymbol{x}_{i}^{\mathrm{f}}$.

Once $\overline{\boldsymbol{x}^{\mathrm{a}}}=\sum_{i=1}^{k} \boldsymbol{x}_{i}^{\mathrm{a}}\left(\boldsymbol{x}_{i}^{\mathrm{a}}\right.$ is the $i$ th member of a $k$-member ensemble analysis) and $\mathbf{P}^{\mathrm{a}}=\frac{1}{k-1} \sum_{i=1}^{k}\left(\boldsymbol{x}_{i}^{\mathrm{a}}-\overline{\boldsymbol{x}^{\mathrm{a}}}\right)\left(\boldsymbol{x}_{i}^{\mathrm{a}}-\overline{\boldsymbol{x}^{\mathrm{a}}}\right)^{\mathrm{T}}$ are computed by Eqs. (10)-(15), there are many choices of an analysis ensemble. Although Eqs. (10)-(15) can calculate the mean and variance of the ensemble members, they do not tell how to adjust the state of the ensemble members in order to realize the estimated mean and variance. There are many proposed flavors of EnKF, and one of the differences among them is the method to choose the analysis $\boldsymbol{x}_{i}^{\mathrm{a}}$. In this paper, the ensemble transform Kalman filter (ETKF; Bishop et al., 2001; Hunt et al., 2007) was used to transport forecast ensembles to analysis ensembles. The ETKF has been used for hyperresolution land data assimilation (e.g., Kurtz et al., 2016). Please refer to Hunt et al. (2007) for the complete description of the ETKF and its localized version, the local ensemble transform Kalman filter (LETKF). The open source available at https://github.com/takemasa-miyoshi/letkf (last access: 31 July 2020) was used in this study as the ETKF code library.

In many ensemble Kalman filter systems, the ensemble spread, $\mathbf{P}^{\mathrm{a}}$, tends to become too underdispersive to stably perform data assimilation cycles without any ensemble inflation methods (Houtekamer and Zhang, 2016). To overcome this limitation, $\mathbf{P}^{\mathrm{a}}$ is arbitrarily inflated after data assimilation. In this paper, the relaxation to prior perturbation method (RTPP) of Zhang et al. (2004) was used to maintain an appropriate ensemble spread. In the RTPP, the computed analysis perturbations are relaxed back to the forecast perturbations:

$\boldsymbol{x}_{i, \text { new }}^{\mathrm{a}}-\overline{\boldsymbol{x}^{\mathrm{a}}}=(1-\alpha)\left(\boldsymbol{x}_{i}^{\mathrm{a}}-\overline{\boldsymbol{x}^{\mathrm{a}}}\right)+\alpha\left(\boldsymbol{x}_{i}^{\mathrm{f}}-\overline{\boldsymbol{x}^{\mathrm{f}}}\right), \quad 0 \leq \alpha \leq 1$,

where $\alpha$ was set to 0.975 in this study. If $\alpha=1$, the analysis spread is identical to the background spread. Many studies show that the ensemble inflation works well when $\alpha$ remains fairly close to 1 (see also the comprehensive review by Houtekamer and Zhang, 2016).

In the data assimilation experiments, I adjusted pressure head by data assimilation so that $\boldsymbol{x}^{\mathrm{f}}$ is pressure head. Since the surface-saturated hydraulic conductivity was also adjusted, $\boldsymbol{x}^{\mathrm{f}}$ includes log-transformed $K_{\mathrm{S} \text {, surface. I assimilated }}$ volumetric soil moisture observations so that $\boldsymbol{y}^{\mathrm{f}}$ and $\boldsymbol{y}^{\mathrm{o}}$ are simulated and observed volumetric soil moisture, respectively. The van Genuchten relationship converts the adjusted state variables $\boldsymbol{x}^{\mathrm{f}}$ to the observable variables $\boldsymbol{y}^{\mathrm{f}}$ and can be recognized as an observation operator $H$. However, since volumetric soil moisture $\boldsymbol{y}^{\mathrm{f}}$ has already been calculated by Parflow, I did not need the van Genuchten relationship in data assimilation.

\subsection{Kullback-Leibler divergence}

To evaluate the non-Gaussianity of the background error sampled by an ensemble, I used the Kullback-Leibler divergence (KLD) (Kullback and Leibler 1951):

$D_{\mathrm{KL}}(p, q)=\sum_{i} p(i) \log \frac{p(i)}{q(i)}$

where $D_{\mathrm{KL}}(p, q)$ is the KLD between two probabilistic distribution functions (PDFs), $p$ and $q$. If two PDFs are equal for all $i, D_{\mathrm{KL}}(p, q)=0$. A large value for $D_{\mathrm{KL}}(p, q)$ indicates that the two PDFs, $p$ and $q$, substantially differ from each other. Therefore, the KLD can be used as an index to evaluate the closeness of two PDFs. In this study, I compared the PDF of the ensemble simulation ( $p$ in Eq. 17) with the Gaussian PDF which has the mean and variance of the ensembles ( $q$ in Eq. 17). A large value for $D_{\mathrm{KL}}(p, q)$ indicates the state variables simulated by ensembles do not follow the Gaussian PDF. It should be noted that the KLD is not symmetric $\left(D_{\mathrm{KL}}(p, q) \neq D_{\mathrm{KL}}(q, p)\right)$. The KLD has been used to quantitatively evaluate the Gaussianity of the sampled background error in the studies on data assimilation (e.g., Kondo and Miyoshi, 2019; Duc and Saito, 2018).

\section{Synthetic experiments}

In this study, I performed two synthetic experiments. In the synthetic experiments, I generated the synthetic truth of the state variables by driving ParFlow with the specified parameters and input data. Then the synthetic observations were generated by adding the Gaussian white noise to this synthetic truth. The performance of data assimilation was evaluated by comparing the estimated state and parameter values by the ETKF with the synthetic truth. This synthetic experiment has been recognized as an important research method to analyze how data assimilation works (e.g., Moradkhani et al., 2005; Camporese et al., 2009; Vrugt et al., 2013; Kurtz et al., 2016; Sawada et al., 2018). 


\subsection{Simple 2-D slope with homogeneous hydraulic conductivity}

\subsubsection{Experiment design}

The synthetic experiment was implemented to examine how topography-driven surface lateral flows contribute to efficiently propagating observation information horizontally in the data assimilation of soil moisture observation. Two synthetic reference runs were created by Parflow. The 2-D domain has a horizontal extension of $4000 \mathrm{~m}$ and a vertical extension of $5 \mathrm{~m}$. The domain of the virtual slope was horizontally discretized into 40 grid cells with a size of $100 \mathrm{~m}$ and vertically discretized into 50 grid cells with a size of $0.10 \mathrm{~m}$. The domain has a $25 \%$ slope. In two synthetic reference runs, it heavily rains only in the upper half of the slope $(2000 \mathrm{~m}<x<4000 \mathrm{~m})$. Although this rainfall distribution is unrealistic, the effect of surface lateral flows on data assimilation can clearly be discussed in this simplified problem setting. More realistic rainfall distribution will be used in the next synthetic experiment (see Sect. 3.2). A constant rainfall rate of $50 \mathrm{~mm} \mathrm{~h}^{-1}$ was applied for $3 \mathrm{~h}$, and then the period with no rainfall and evaporation of $0.075 \mathrm{~mm} \mathrm{~h}^{-1}$ lasted for $117 \mathrm{~h}$. This $120 \mathrm{~h}$ rain-no rain cycle was repeatedly applied to the domain. There is no rainfall in the lower half of the slope $(0 \mathrm{~m}<x<2000 \mathrm{~m})$. The configurations described above were schematically shown in Fig. 1a. The parameters of the van Genuchten relationship, $\alpha$ and $n$, were set to $1.5\left(\mathrm{~m}^{-1}\right)$ and 1.75 , respectively. Those values are in the reasonable range estimated by the published literature (e.g., Ghanbarian-Alavijeh et al., 2010). The porosity, $\phi$ in Eq. (1), was set to 0.40 . The Manning coefficient, $n_{\mathrm{M}}$ in Eq. (7), was set to $5.52 \times 10^{-6}\left(\mathrm{~m}^{-1 / 3} \mathrm{~h}\right)$. These clayey soil properties described above are applied to the whole domain. The groundwater table was located at $z=3 \mathrm{~m}$ and the hydrostatic pressure gradient was assumed for the initial pressure heads in the unsaturated soil layers.

The difference between two synthetic reference runs is the value of saturated hydraulic conductivity. The surfacesaturated hydraulic conductivity, $K_{\mathrm{s} \text {,surface }}$ in Eq. (3), was set to $0.005\left(\mathrm{~m} \mathrm{~h}^{-1}\right)$ in one reference and to $0.02\left(\mathrm{~m} \mathrm{~h}^{-1}\right)$ in the other. These surface-saturated hydraulic conductivities described above are applied to the whole domain. Figure 1 shows the difference of the response to heavy rainfall between the two synthetic reference runs. In the case of the low saturated hydraulic conductivity (hereafter called the LOW_K reference), larger surface lateral flows are generated than the case of the high saturated hydraulic conductivity (hereafter called the HIGH_K reference). In the LOW_K reference, the topography-driven surface lateral flows reach the left edge of the domain (Fig. 1b). In the HIGH_K reference, supplied water moves vertically rather than horizontally and the topography-driven surface flow reaches around $x=1000-1500 \mathrm{~m}$ (Fig. 1d).
For the data assimilation experiment, an ensemble of 50 realizations was generated. Each ensemble member has a different saturated hydraulic conductivity and rainfall rate. Lognormal multiplicative noise was added to the surfacesaturated hydraulic conductivity and rainfall rate of the synthetic reference runs. This specification of uncertainty in rainfall was also adopted in Crow et al. (2011). The two parameters of the lognormal distribution, commonly called $\mu$ and $\sigma$, were set to 0 and 0.15 , respectively. These parameters were chosen to give the sufficiently large error in precipitation and saturated hydraulic conductivity. In addition, this setting makes the rainfall PDF similar to the Gaussian distribution, which is important for interpreting the results of the experiments (see the discussion section). The initial groundwater depth of each ensemble member was drawn from the uniform distribution from 2.0 to $3.5 \mathrm{~m}$. The hydrostatic pressure gradient was assumed for the initial pressure heads in the unsaturated soil layers.

The virtual hourly observations were generated by adding the Gaussian white noise whose mean is zero to the volumetric soil moisture simulated by the synthetic reference runs. The observation error (the standard deviation of the added Gaussian white noise) was set to $0.05 \mathrm{~m}^{3} \mathrm{~m}^{-3}$. It was assumed that the volumetric soil moisture can be observed in every model's soil layer from the surface to the depth of $1 \mathrm{~m}$ at the specific location. These soil moisture observations can be obtained in the in situ observation sites (e.g., Dorigo et al., 2017). In Sect. 3.2, I will assume that only surface soil moisture observation can be accessed, which is more realistic since satellite sensors can observe only surface soil moisture. I assumed that the small part of the domain can be observed. The two scenarios of the observation's location are provided. In the first scenario (hereafter called the UP_O scenario), the volumetric soil moisture in the upper part of the slope $(x=2500 \mathrm{~m})$ was observed. In the UP_O scenario, I could observe the volumetric soil moisture in the upper part of the slope where it heavily rains and tried to infer the soil moisture in the lower part of the slope where it does not rain by propagating the observation's information downhill. In the second scenario (hereafter called the DOWN_O scenario), the volumetric soil moisture in the lower part of the slope $(x=1500 \mathrm{~m})$ was observed. In the DOWN_O scenario, I could observe the volumetric soil moisture in the lower part of the slope where it does not rain and tried to infer the soil moisture in the upper part of the slope where it heavily rains by propagating the observation's information uphill.

Since I had the two synthetic reference runs (the HIGH_K and LOW_K references) and the two observation scenarios (the UP_O and DOWN_O scenarios), I implemented a total of four data assimilation experiments. Table 1 summarizes the data assimilation experiments implemented in this study. For instance, in the HIGH_K-UP_O experiment, I chose the HIGH_K reference and generated an ensemble of 50 realizations from the HIGH_K reference. The soil moisture observations were generated from the HIGH_K reference at 

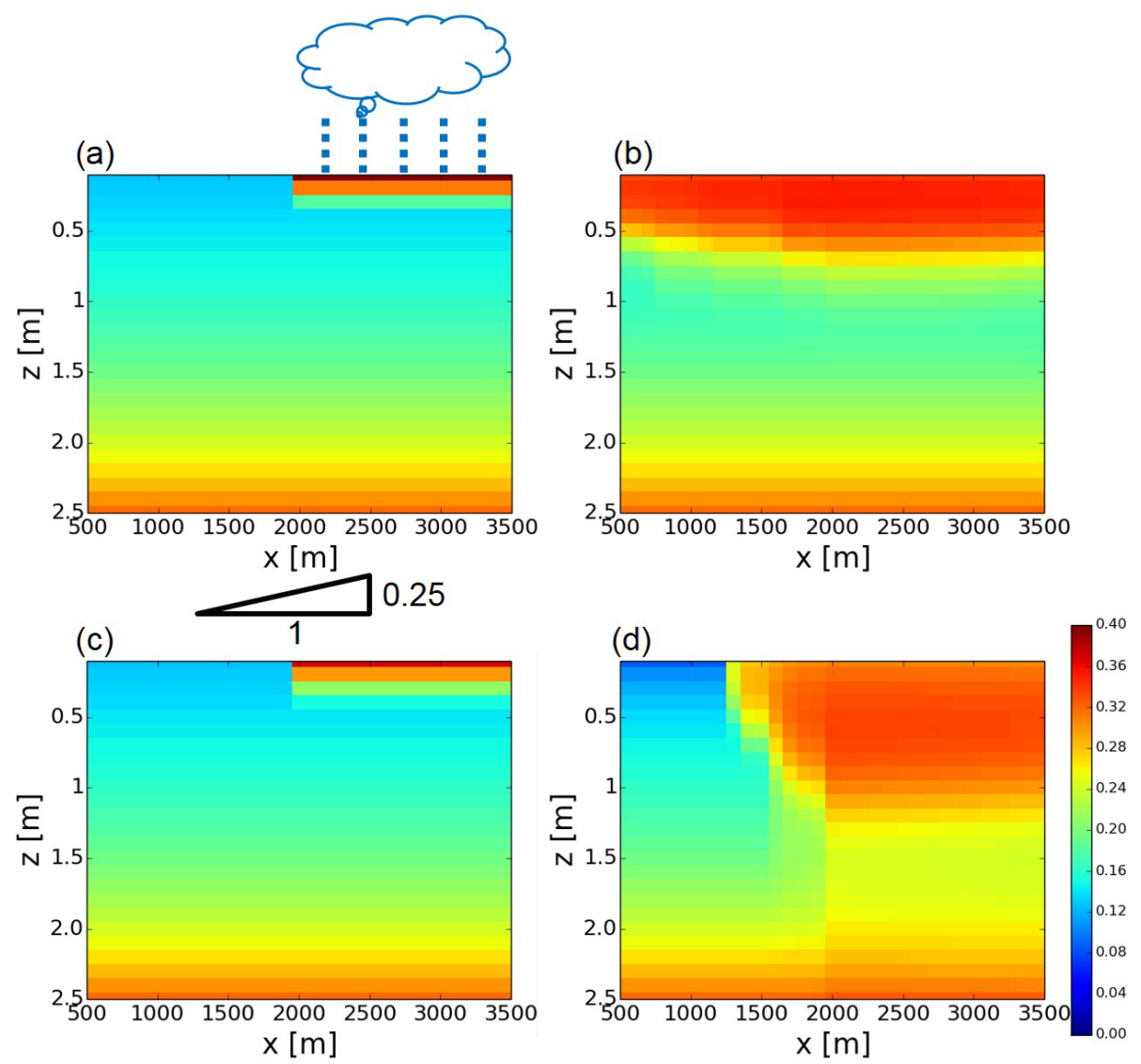

Figure 1. Distributions of volumetric soil moisture simulated by the synthetic reference runs. (a) The distribution of volumetric soil moisture $\left(\mathrm{m}^{3} \mathrm{~m}^{-3}\right)$ simulated by the LOW_K synthetic reference run at $t=0 \mathrm{~h}$. The schematic of the configuration of the synthetic reference runs is also shown (see also Sect. 3). (b) Same as (a) but at $t=130 \mathrm{~h}$. (c, d) Same as (a, b) but for the HIGH_K synthetic reference run.

Table 1. Configuration of the data assimilation experiments in Sect. 3.1.

\begin{tabular}{lrc}
\hline & $\begin{array}{r}\text { Hydraulic } \\
\text { conductivity } \\
\left(\mathrm{m} \mathrm{h}^{-1}\right)\end{array}$ & $\begin{array}{c}\text { Observation's } \\
\text { location } \\
(\mathrm{m})\end{array}$ \\
\hline LOW_K-UP_O & 0.005 & 2500 \\
LOW_K-DOWN_O & 0.005 & 1500 \\
HIGH_K-UP_O & 0.02 & 2500 \\
HIGH_K-DOWN_O & 0.02 & 1500 \\
\hline
\end{tabular}

the location of $x=2500 \mathrm{~m}$ and assimilated into the model every hour. The simulated volumetric soil moisture of the data assimilation experiment was compared with that of the HIGH_K reference.

In addition to the data assimilation (DA) experiments, I implemented the NoDA experiment (also called the openloop experiment in the literature of the LDAS study) in which the ensemble was used but no observation data were assimilated. Please note that in the NoDA experiment, the true rainfall rate and saturated hydraulic conductivity were unknown, so that I could not accurately estimate the synthetic true state variables. I will evaluate how this negative impact of uncertainties in rainfall and saturated hydraulic conductivity can be mitigated by data assimilation in the DA experiment.

As an evaluation metric, root-mean-square error (RMSE) was used:

$\mathrm{RMSE}=\sqrt{\frac{1}{k} \sum_{i=1}^{k}\left(F_{i}-T\right)^{2}}$,

where $k$ is the ensemble number, $F_{i}$ is the volumetric soil moisture simulated by the $i$ th member in the DA or NoDA experiment, and $T$ is the volumetric soil moisture simulated by the synthetic reference run. I used all ensemble members to calculate RMSE because I should evaluate not only whether the ensemble mean is consistent with the synthetic truth, but also whether the extremely large ensemble spread simulated in the NoDA experiment is appropriately reduced.

To evaluate the impact of data assimilation, the improvement rate (IR) was defined and calculated by the following equation: 

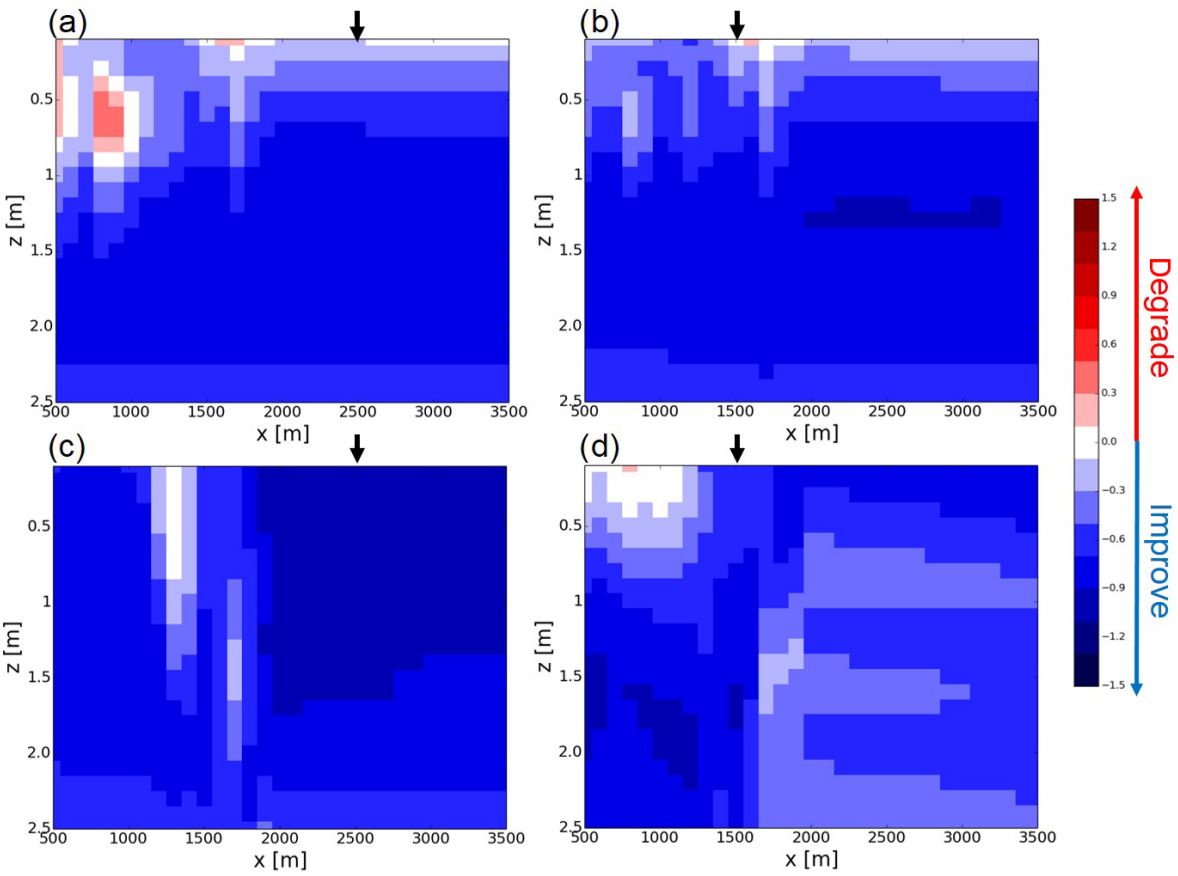

Figure 2. The improvement rates of the (a) LOW_K-UP_O, (b) LOW_K-DOWN_O, (c) HIGH_K_UP_O, and (d) HIGH_K-DOWN_O experiments (see Table 1 and Sect. 3). Black arrows show the locations of the soil moisture observations in each experiment.

$$
\mathrm{IR}=\frac{\overline{\mathrm{RMSE}_{\mathrm{DA}}}-\overline{\mathrm{RMSE}_{\mathrm{NoDA}}}}{\overline{\mathrm{RMSE}_{\mathrm{NoDA}}}},
$$

where $\overline{\mathrm{RMSE}_{\mathrm{DA}}}$ and $\overline{\mathrm{RMSE}_{\mathrm{NoDA}}}$ are the time-mean RMSEs of the DA and NoDA experiments, respectively. The negative IR indicates that data assimilation positively impacts the simulation of soil moisture. The metrics described above were calculated in the whole domain. In the DA experiment, soil moisture values before the update by ETKF (i.e., initial guess) were used to calculate the metrics.

Four of the $120 \mathrm{~h}$ rain-no rain cycles were applied so that the computation period was $480 \mathrm{~h}$. The spin-up results in the first $120 \mathrm{~h}$ were not used to calculate the evaluation metrics. Since the steady state of groundwater level is not within the scope of this paper, the long spin-up is not absolutely necessary.

\subsubsection{Results}

Figure 2a shows the IR of the LOW_K-UP_O experiment. The time series of the DA and NoDA experiments and the synthetic reference run in the LOW_K-UP_O experiment can be found in Fig. S1 in the Supplement. The data assimilation efficiently propagates the information of the observations located in the upper part of the slope (see the black arrow in Fig. 2a) both horizontally and vertically. Despite the uncertainty in rainfall and hydraulic conductivity, RMSE is reduced by data assimilation not only directly under the observation, but also the lower part of the slope where it does not rain. The estimated $K_{\mathrm{s} \text {, surface }} \approx 0.00508\left(\mathrm{~m} \mathrm{~h}^{-1}\right)$ by ETKF is mostly identical to the synthetic truth. However, the increase in RMSE by data assimilation can be found at the left edge of the domain, which is far from the location of the observation. The impact of data assimilation on the surface soil moisture simulation is small because the volumetric soil moisture's RMSE of the NoDA experiment in this surface soil layer is already small $\left(\leq 0.01 \mathrm{~m}^{3} \mathrm{~m}^{-3}\right)$ in the case of the LOW_K reference, so that any improvements do not make sense.

Figure $2 b$ shows the IR of the LOW_K-DOWN_O experiment (see also Fig. S2 for time series). The IR's spatial pattern of the LOW_K-DOWN_O experiment is similar to that of the LOW_K-UP_O experiment except for the left edge of the domain. It is promising that I can accurately infer soil moisture in the region where it heavily rains from the shallow soil moisture observations in the region where it does not rain. The estimated $K_{\mathrm{s} \text {, surface }} \approx 0.00512\left(\mathrm{~m} \mathrm{~h}^{-1}\right)$ by ETKF is mostly identical to the synthetic truth.

Figure 3a shows the difference of time-mean RMSEs $\left(\overline{\mathrm{RMSE}_{\mathrm{DA}}}\right.$ in Eq. 18) between the LOW_K-UP_O and LOW_K-DOWN_O experiments. Although observing the lower part of the slope slightly improves the soil moisture simulation at the left edge of the domain compared with observing the upper part of the slope (the reason for this will be explained later), there are few differences between the UP_O and DOWN_O scenarios in the case of the LOW_K reference. The soil moisture observations have large representativeness and I can efficiently infer soil moisture in the soil 
columns which are horizontally and vertically far from the observations.

Figure 2c shows the IR of the HIGH_K-UP_O experiment (see also Fig. S3 for time series). The data assimilation significantly reduces RMSE of the soil moisture simulation directly under the observations (see the black arrow in Fig. 2c), which indicates that the data assimilation efficiently propagates the information of the observations vertically. The saturated hydraulic conductivity estimated by ETKF is mostly identical to the synthetic truth $\left(K_{\mathrm{s}, \text { surface }} \approx 0.0204-\mathrm{m} \mathrm{h}^{-1}\right)$. However, the impact of the data assimilation on the soil moisture simulation in the lower part of the slope around $x=1500 \mathrm{~m}$ is marginal, although there are large RMSEs in the NoDA experiment $\left(>0.05 \mathrm{~m}^{3} \mathrm{~m}^{-3}\right)$ at the edge of the area where topography-driven surface flow reaches in the HIGH_K reference (see Fig. 1d).

Figure 2d shows the IR of the HIGH_K-DOWN_O experiment (see also Fig. S4 for time series). Although the observations in the lower part of the slope (see the black arrow in Fig. 2d) significantly contribute to improving the soil moisture simulation in the downstream area of the observation and accurately estimating $K_{\mathrm{s} \text {, surface }} \approx 0.0208\left(\mathrm{~m} \mathrm{~h}^{-1}\right)$, the impact of the data assimilation on the shallow soil moisture simulation around $x=500-1000 \mathrm{~m}$ is marginal. As I found in the LOW_K-DOWN_O experiment, the shallow soil moisture observations in the region where it does not rain can improve the soil moisture simulation in the region where it heavily rains. However, the IR of the HIGH_K-DOWN_O experiment in the upper part of the slope is smaller than that of the LOW_K-DOWN_O experiment (see Fig. 2b and d).

The high representativeness of the observations which I found in the case of the LOW_K reference (i.e., the small difference of RMSEs between two observation scenarios) cannot be found in the case of the HIGH_K reference. Figure $3 b$ shows the difference of time-mean RMSEs ( $\overline{\mathrm{RMSE}_{\mathrm{DA}}}$ in Eq. 18) between the HIGH_K-UP_O and HIGH_K-DOWN_O experiments. Compared with the LOW_K reference case (Fig. 3a), there are significant differences between the UP_O and DOWN_O scenarios in the case of higher saturated hydraulic conductivity. In this case, the vertical propagation of the observations' information is more efficient than the horizontal propagation.

The relatively low efficiency of the data assimilation and the low representativeness of the soil moisture observations in the case of the HIGH_K reference are caused by the nonGaussian background error distribution. I calculated KLD by comparing the PDF of the NoDA ensemble ( $p$ in Eq. 17) with the Gaussian PDF which has the mean and variance of the NoDA ensemble ( $q$ in Eq. 17). Figure 4 shows that the NoDA ensemble in the case of the HIGH_K reference has stronger non-Gaussianity than the case of the LOW_K reference, especially in the shallow soil layers. The strong non-Gaussianity of the NoDA ensemble generated from the HIGH_K reference can be found at the edge of the area where the topography-driven surface flow reaches (Fig. 1d).
Figure 5 shows that there is bifurcation of the ensemble in this region when the ensemble is generated from the HIGH_K reference. The process of topography-driven surface flows is switched on if and only if the surface soil is saturated (see Eq. 6), so that the ensemble tends to be bifurcated into the members with surface flows and without surface flows. As I mentioned in Sect. 2.2, in the ETKF, the estimation of the state and parameter variables is optimal if and only if the model's error has the Gaussian PDF and the relationship between observed variables and unobserved variables is linear. Therefore, the non-Gaussianity of the prior ensemble induced by the strong nonlinear dynamics of surface lateral flows makes the ETKF inefficient. It is more difficult to reconstruct 3-D fields of soil moisture in highconductivity soils since the 1-D vertical water movement is more dominant. The absolute RMSE of the NoDA experiment in the HIGH_K reference is larger than the LOW_K reference in many places (not shown). Please note that the non-Gaussianity can also be found in the LOW_K reference at the edge of the domain $(x=500 \mathrm{~m})$ due to the nonlinear dynamics of surface lateral flows, which causes the degradation of the soil moisture simulation in the LOW_K-UP_O experiment (see Fig. 2a).

One of the major simplifications in this experiment is spatially homogeneous surface-saturated hydraulic conductivity. The optimization of it can efficiently improve the soil moisture simulation in the whole domain. However, the optimization of this homogeneous surface-saturated hydraulic conductivity has a limited impact on the soil moisture simulation. Figure S5 shows the IR of the HIGH_K-DOWN_O experiment where the parameter optimization by ETKF is switched off. Even if I do not optimize the surface-saturated hydraulic conductivity, I could obtain a similar IR to the original experiment, and the shallow soil moisture observations in the region where it does not rain can improve the soil moisture simulation in the region where it heavily rains. The horizontal propagation of the observations' information shown in this experiment was brought out not only by the estimation of spatially homogeneous saturated hydraulic conductivity, but also by the adjustment of state variables (i.e., pressure head and volumetric soil moisture).

Please note that the improvement of the soil moisture simulation cannot be found if the topography-driven surface flow is neglected. Figure S6 shows the IR of the LOW-K_DOWN$\mathrm{O}$ experiment where the topography-driven surface flow is neglected in the ParFlow simulation. Please note that although many conventional land surface models neglected or parameterized lateral flows, this assumption can be applied only in the coarse spatial resolution $(>25 \mathrm{~km}$ ), which is not the case of this experimental setting. The imperfect model physics of ParFlow substantially degrades the skill to simulate soil moisture, and data assimilation cannot compensate for this degradation. This point will also be discussed in Sect. 3.2 in more depth. 


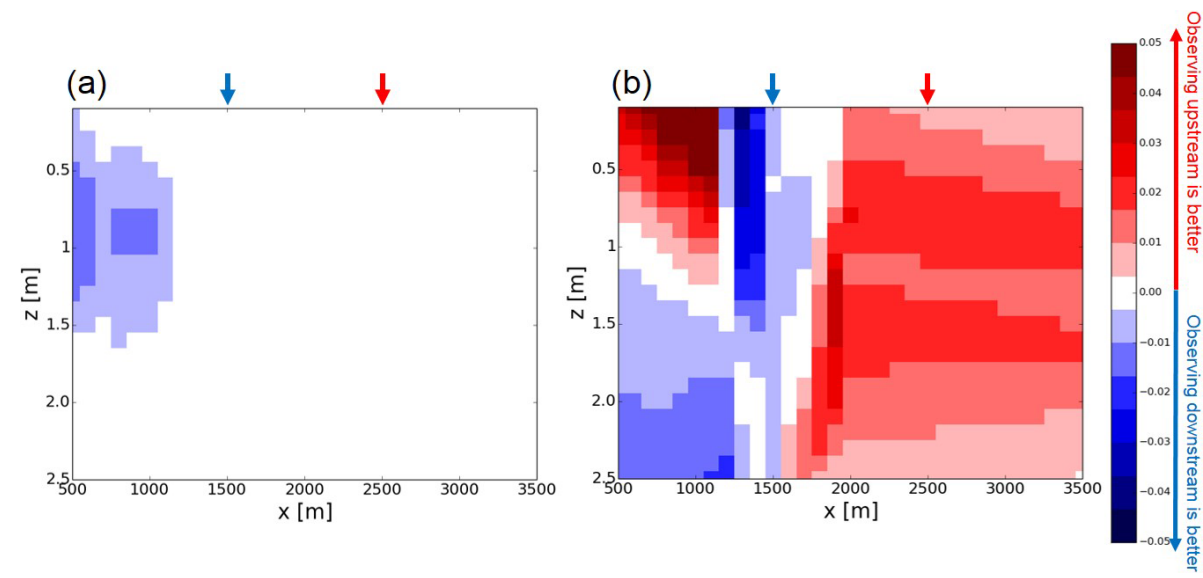

Figure 3. (a) The difference of time-mean RMSEs between the LOW_K-UP_O and LOW_K-DOWN_O experiments (see Table 1 and Sect. 3). Red (blue) color indicates that the observations in the upper (lower) part of the slope reduce time-mean RMSE by data assimilation better than those in the lower (upper) part of the slope (see also arrows, which are the locations of the observations). (b) Same as (a) but for the difference between the HIGH_K-UP_O and HIGH_K-DOWN_O experiments.
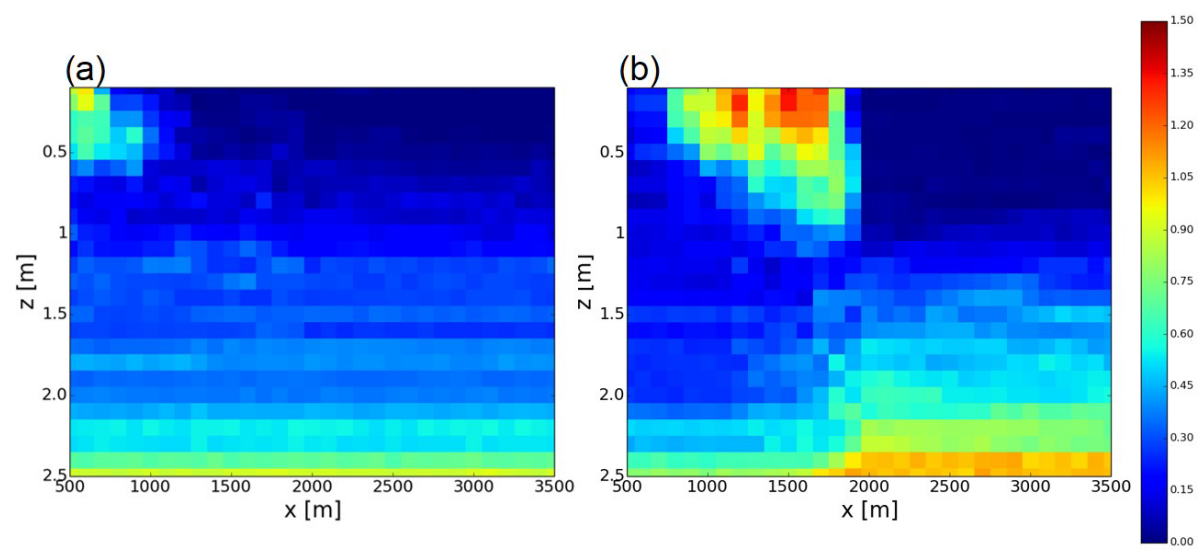

Figure 4. The Kullback-Leibler divergence of the NoDA experiment generated by (a) the LOW_K reference and (b) the HIGH_K reference at $t=130 \mathrm{~h}$ (see also Fig. 1b and d).

\subsection{Simple 3-D slope with heterogeneous hydraulic conductivity}

\subsubsection{Experiment design}

To further demonstrate how land data assimilation works with topography-driven surface lateral flows, I implemented another synthetic experiment which is more realistic than that shown in Sect. 3.1. The 3-D domain has a horizontal extension of $4000 \mathrm{~m} \times 4000 \mathrm{~m}$ and a vertical extension of $3 \mathrm{~m}$. The domain was horizontally discretized into $40 \times 40$ grid cells with a size of $100 \mathrm{~m} \times 100 \mathrm{~m}$ and vertically discretized into 30 grid cells with a size of $0.1 \mathrm{~m}$. The domain has a $10 \%$ slope in both the $x$ and $y$ directions (see Fig. 6a). The parameters of the van Genuchten relationship, porosity and Manning coefficient were set to the same variables for the synthetic experiment in Sect. 3.1.
The spatially heterogeneous surface-saturated hydraulic conductivity was generated following Kurtz et al. (2016). The field of $\log _{10}\left(K_{\mathrm{s} \text {, surface }}\right)$ was generated by 2-D unconditioned sequential Gaussian simulation. A Gaussian variogram with nugget, sill, and range values of $0.0 \log _{10}\left(\mathrm{~m} \mathrm{~h}^{-1}\right), 0.1 \log _{10}\left(\mathrm{~m}^{2} \mathrm{~h}^{-2}\right)$, and 12 model grids $(1200 \mathrm{~m})$, respectively, was used to simulate the spatial distribution of $\log _{10}\left(K_{\mathrm{s} \text {, surface }}\right)$. A constant value of $-2.30 \log _{10}\left(\mathrm{~m} \mathrm{~h}^{-1}\right)$ (i.e., $\left.0.005\left(\mathrm{~m} \mathrm{~h}^{-1}\right)\right)$ was added to the generated field so that the mean of the logarithm of surface-saturated hydraulic conductivity was set to -2.30 (i.e., $\left.0.005\left(\mathrm{~m} \mathrm{~h}^{-1}\right)\right)$. This method to generate the field of the saturated hydraulic conductivity has been used previously (e.g., Kurtz et al., 2016). Subsurface-saturated hydraulic conductivity was calculated by Eq. (3). An ensemble of 51 realizations of $\log _{10}\left(K_{\mathrm{s}, \text { surface }}\right)$ was generated, and 1 of them was 
(a)

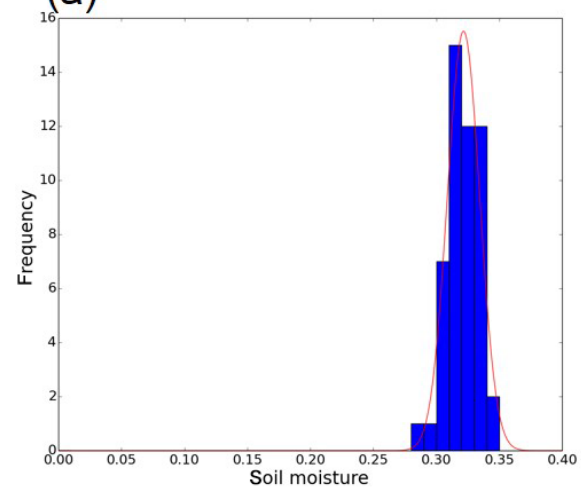

(c)

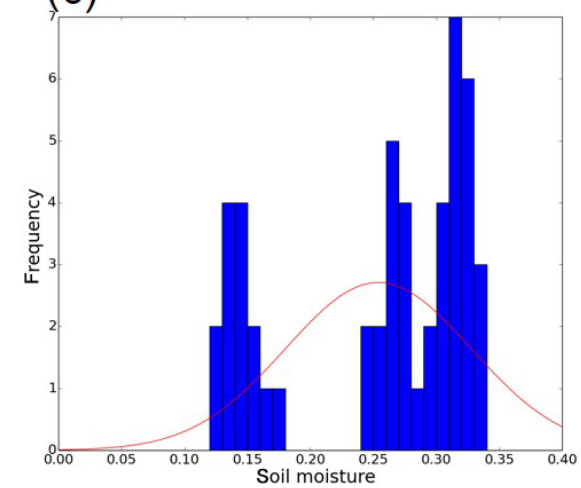

(b)

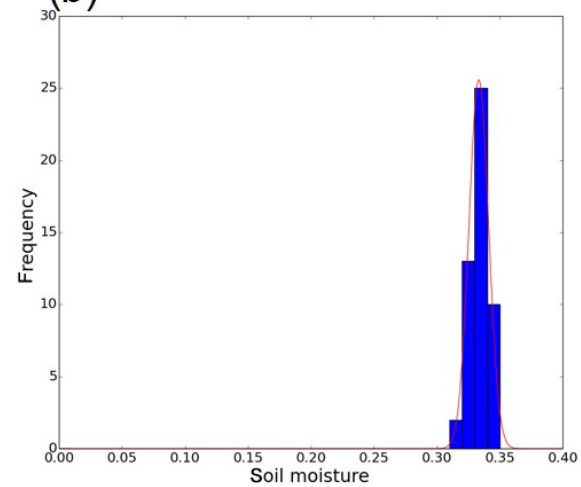

(d)

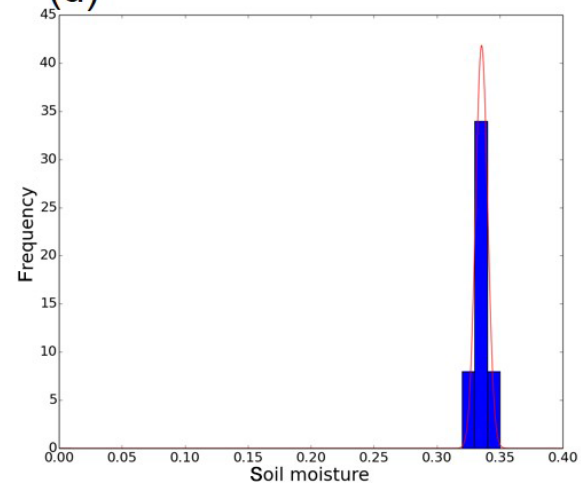

Figure 5. (a) The histogram (blue bars) of the volumetric soil moisture simulated by the NoDA experiment (see Sect. 3) with the LOW_K reference at $x=1500 \mathrm{~m}, z=0.5 \mathrm{~m}$, and $t=130 \mathrm{~h}$ (see also Fig. 4). Red line shows the Gaussian distribution with the mean and variance sampled by the ensemble. (b) Same as (a) but at $x=2500 \mathrm{~m}, z=0.5 \mathrm{~m}$, and $t=130 \mathrm{~h}$. (c) Same as (a) but for the HIGH_K reference. (d) Same as (c) but at $x=2500 \mathrm{~m}, z=0.5 \mathrm{~m}$, and $t=130 \mathrm{~h}$.
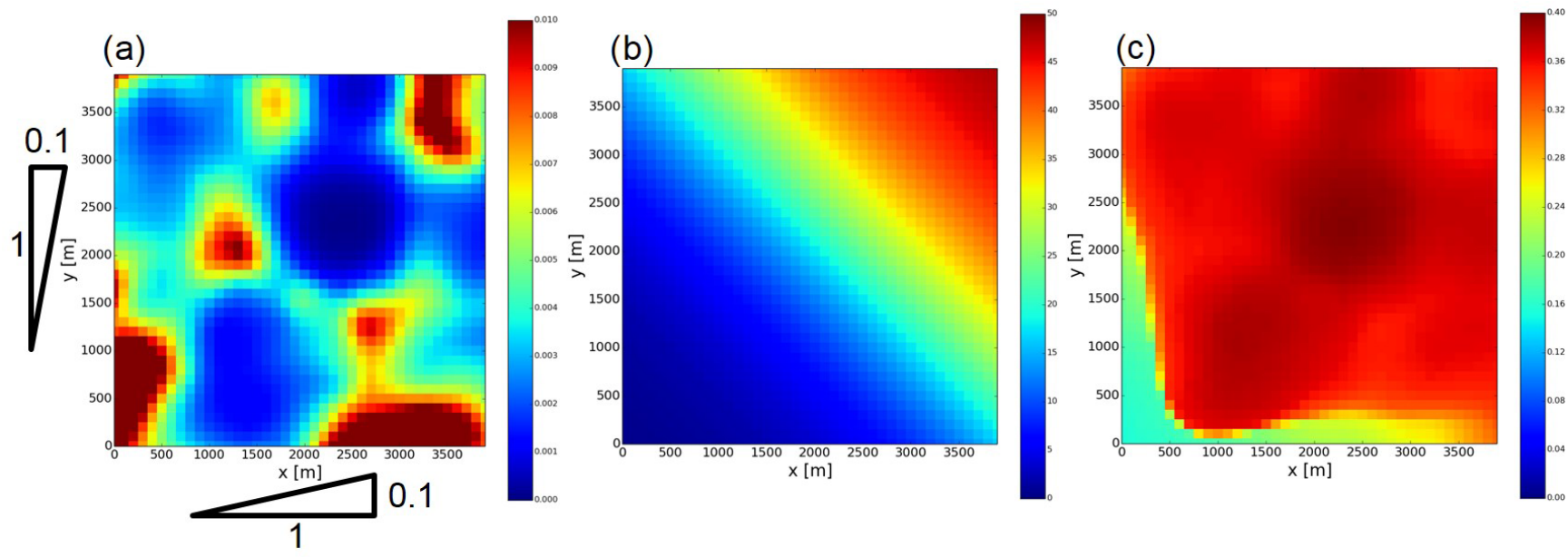

Figure 6. (a) Distribution of surface-saturated hydraulic conductivity $\left(\mathrm{m} \mathrm{h}^{-1}\right)$ in the synthetic reference. (b) Distribution of rainfall rate $\left(\mathrm{mm} \mathrm{h}^{-1}\right)$ in the synthetic reference. (c) Surface volumetric soil moisture $\left(\mathrm{m}^{3} \mathrm{~m}^{-3}\right)$ at $t=5(\mathrm{~h})$ in the synthetic reference.

chosen as a synthetic reference (Fig. 6a). The remaining 50 members were used for data assimilation experiments.
A rainfall rate $R(x, y)\left(\mathrm{mm} \mathrm{h}^{-1}\right)$ was modeled by a logistic function:

$$
R(x, y)=\frac{R_{\max }}{1+100 \exp \left(-0.2 \times \frac{x+y}{2}\right)},
$$


where $x$ and $y$ are horizontal grid numbers $(1 \leq x \leq 40$, $1 \leq y \leq 40)$. In the synthetic reference, the maximum rainfall rate in the domain, $R_{\max }$, was set to $50\left(\mathrm{~mm} \mathrm{~h}^{-1}\right)$ (Fig. 6b). This rainfall rate was applied for $3 \mathrm{~h}$ and then the period with no rainfall and evaporation of $0.075 \mathrm{~mm} \mathrm{~h}^{-1}$ lasted for $117 \mathrm{~h}$. For the data assimilation experiment, an ensemble of 50 realizations of $R(x, y)$ was generated by adding a lognormal multiplicative noise to $R_{\max }$ of the synthetic reference. The two parameters of the lognormal distribution, commonly called $\mu$ and $\sigma$, were set to 0 and 0.15 , respectively.

Figure $6 \mathrm{c}$ shows the distribution of surface soil moisture in the synthetic reference run. A strong rainfall rate applied in the upper part of the slope generates the topography-driven surface lateral flows. The virtual hourly observations were generated by adding the Gaussian white noise, whose mean is zero and standard deviation is $0.05 \mathrm{~m}^{3} \mathrm{~m}^{-3}$, to the volumetric surface soil moisture simulated by the synthetic reference run. Unlike the experiment in Sect. 3.1, only surface soil moisture can be observed in this synthetic experiment, which makes this experiment more realistic since satellite sensors can observe only surface soil moisture. Three different observing networks with different observation densities were used (Fig. 7). The observing networks shown in Fig. 7a-c have in total 1, 9, and 361 observations and are called obs1, obs9, and obs361, respectively.

In the DA experiments, those virtual observations of surface soil moisture were assimilated every hour to adjust pressure head and saturated hydraulic conductivity. As I did in Sect. 3.1, the NoDA experiments were also implemented. The two different configurations of ParFlow were used for both DA and NoDA experiments. In the first configuration, called OF (Overland Flow), Parflow explicitly solves overland flows. In the second configuration, called noOF, Parflow assumes the flat terrain for surface flows so that no overland flows are generated. Since the synthetic reference run explicitly considers the topography-driven surface flow, the configuration of noOF assumes that the model physics is imperfect. I implemented eight numerical experiments which are summarized in Table 2. For example, the OF_DA_obs9 experiment is the data assimilation experiment with the observing network shown in Fig. 7b, in which Parflow explicitly solves the topography-driven surface flow. The noOF_NoDA is the model run without assimilating observations, in which Parflow does not consider the topography-driven surface flow.

\subsubsection{Results}

Figure 8a shows the RMSE of soil moisture simulation of a second soil layer (i.e., $10-20 \mathrm{~cm}$ soil depth) in all eight experiments (the same conclusion described below can be obtained by analyzing all of the shallow soil layers). When Parflow explicitly solves the topography-driven surface flow, data assimilation substantially reduces the RMSE of the soil moisture simulation (green bars in Fig. 8a). The
Table 2. Configuration of the data assimilation experiments in Sect. 3.2.

\begin{tabular}{lll}
\hline & Overland flows & Observing network \\
\hline noOF_NoDA & None & No data assimilation \\
noOF_DA_obs1 & None & Fig. 7a \\
noOF_DA_obs9 & None & Fig. 7b \\
noOF_DA_obs361 & None & Fig. 7c \\
OF_NoDA & Simulated & No data assimilation \\
OF_DA_obs1 & Simulated & Fig. 7a \\
OF_DA_obs9 & Simulated & Fig. 7b \\
OF_DA_obs361 & Simulated & Fig. 7c \\
\hline
\end{tabular}

OF_DA_obs361 experiment has the smallest RMSE, so that a denser observing network is beneficial for estimating soil moisture, although there is the stalled improvement from the OF_DA_obs1 experiment to the OF_DA_obs9 experiment (the reason for it will be explained later). Figure $8 \mathrm{~b}$ shows the RMSE of the estimation of saturated surface hydraulic conductivity in all eight experiments. Data assimilation also reduces the uncertainty in the model's parameters (green bars in Fig. 8b). However, the OF_DA_obs361 experiment has a larger RMSE than the other DA experiments. This is because the adjustment of hydraulic conductivity in the OF_DA_obs361 experiment greatly mitigates not only the errors induced by uncertainty in hydraulic conductivity, but also those induced by uncertainty in rainfall rate. In the OF configuration, there are two sources of errors, rainfall rate and hydraulic conductivity. However, data assimilation can adjust only hydraulic conductivity in this study. Although it is expected that the adjustment of hydraulic conductivity mainly mitigates the errors of simulated volumetric soil moisture induced by uncertainty in hydraulic conductivity, it also greatly mitigates those induced by uncertainty in rainfall rate by adjusting the parameter in the incorrect direction when the number of observations is large. Therefore, the assimilation of a large number of observations degrades the estimation of saturated hydraulic conductivity despite the improvement of the soil moisture simulation.

The noOF_NoDA experiment has a larger RMSE than the OF_NoDA experiment due to the negligence of the topography-driven surface flow. In the noOF configuration, data assimilation also improves the soil moisture simulation (red bars in Fig. 8a). The noOF_DA_obs361 experiment outperforms the OF_NoDA experiment, so that data assimilation with a dense observing network can compensate for the negative impact of neglecting the topography-driven surface flow. Although data assimilation positively impacts the parameter estimation, the denser observing network cannot re- 
(a)

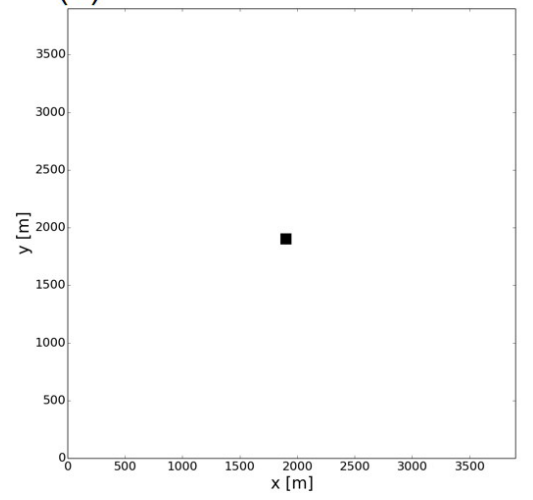

(b)

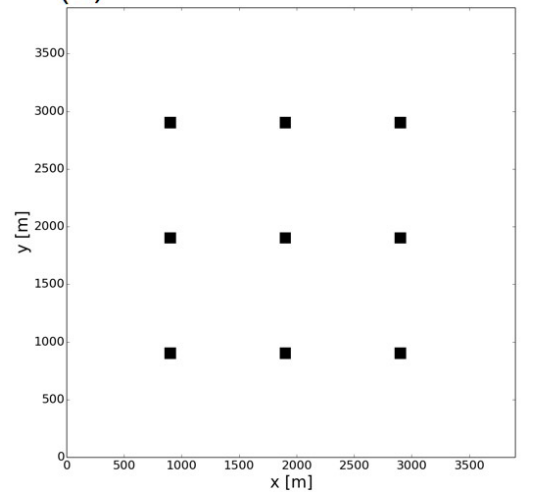

(c)

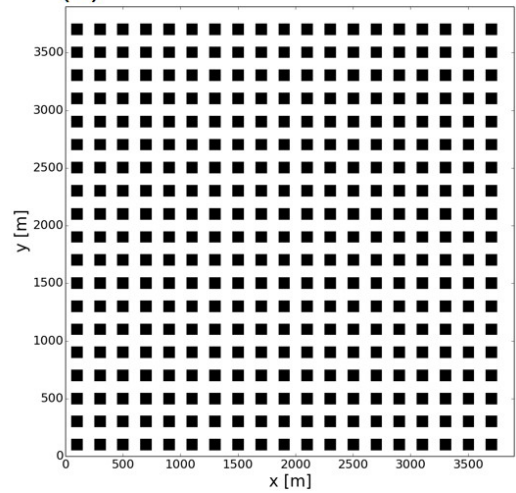

Figure 7. Observing networks. Black boxes are observed grids. (a) obs1, (b) obs9, and (c) obs361. See also Sect. 3.2.1.
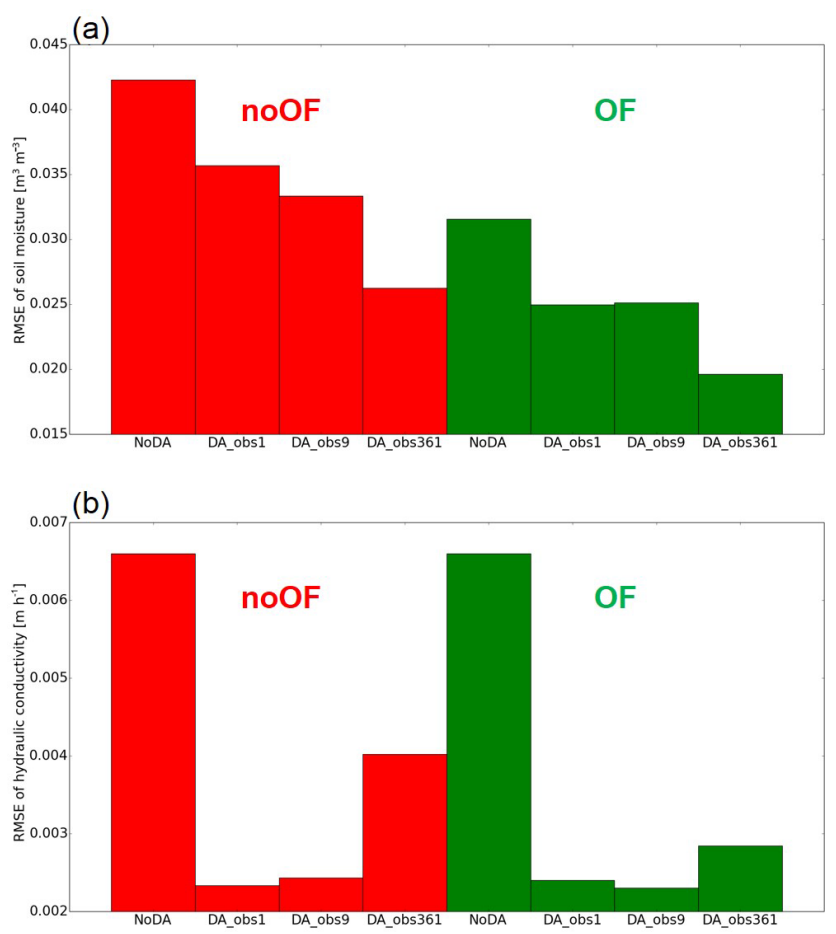

Figure 8. Time-mean RMSEs of the estimation of (a) soil moisture and (b) hydraulic conductivity. Red and green bars are results of the noOF and OF configurations, respectively (see Sect. 3.2.1 and Table 2).

duce the RMSE of hydraulic conductivity estimation (red bars in Fig. 8b). The negative impact of the dense observations in the noOF_DA_obs361 experiment on the parameter estimation is larger than in the OF_DA_obs361 experiment. In addition to rainfall rate and hydraulic conductivity, the imperfect model physics (i.e., no topography-driven surface flow) is the source of error in the noOF configuration. The assimilation of a large number of observations degrades the estimation of saturated hydraulic conductivity be- cause it greatly mitigates the impact of all systematic errors which comes from three different sources only by adjusting hydraulic conductivity.

Figure 9 shows the difference of RMSE of the soil moisture simulation between the DA experiments and the OF_NoDA experiment. In the DA configuration, the improvement of the soil moisture estimation can be found in a large area even if there is a single observation in the center of the domain (Fig. 9a). Figure 9b shows that the increase in the number of observations substantially improves the soil moisture simulation in the region which is affected by topography-driven surface flow (see also Fig. 6c). However, the skill to simulate soil moisture is severely degraded in the lower-left corner of the domain, which causes the stalled improvement from the OF_DA_obs1 experiment to the OF_DA_obs9 experiment shown in Fig. 8a. Figure 9c shows that although the far denser observing network can slightly mitigate this degradation, increasing the number of observations cannot efficiently solve this issue. This degradation is caused by the bifurcation of ensemble members at the edge of the area where topography-driven surface flow reaches (Fig. S7). Figure 10 shows KLD in the OF_NoDA and noOF_NoDA experiments. Figure 10a clearly shows that the ensemble simulation of volumetric soil moisture generates the strong non-Gaussianity at the edge of the area where topography-driven surface flow reaches, which harms the efficiency of the ETKF. This finding is consistent with what I found in the previous experiment in Sect. 3.1.

In the noOF configuration, there are large errors in the area around $500 \leq x, y \leq 1500$ (not shown) since the increase in soil moisture in this area is caused by the topographydriven surface flow which is neglected in the noOF configuration. Figure $9 \mathrm{~d}$ and e show that the sparse observations cannot completely remove this degradation caused by imperfect model physics. Figure 9f shows that the noOF_DA_obs361 can outperform the OF_NoDA experiment in exchange for the degradation of the parameter estimation as I found in Fig. 8. The unstable behavior of the ETKF found in the 
(a)

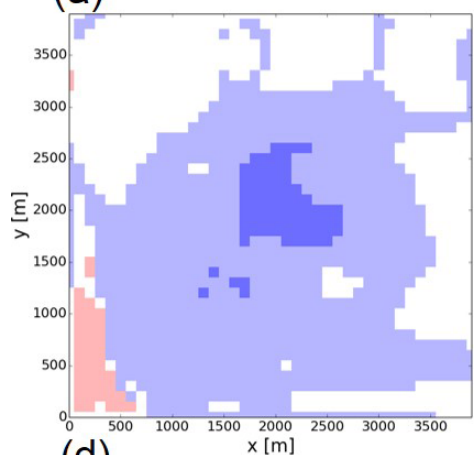

(d)

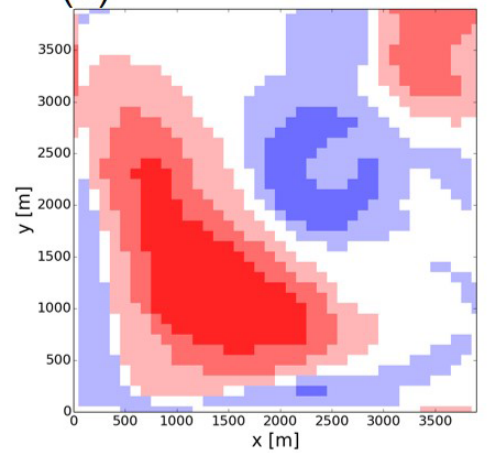

(b)

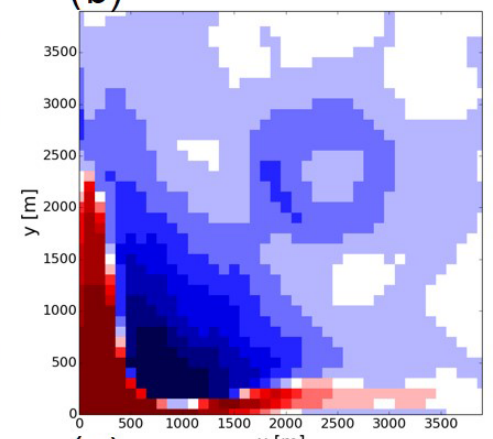

(e)

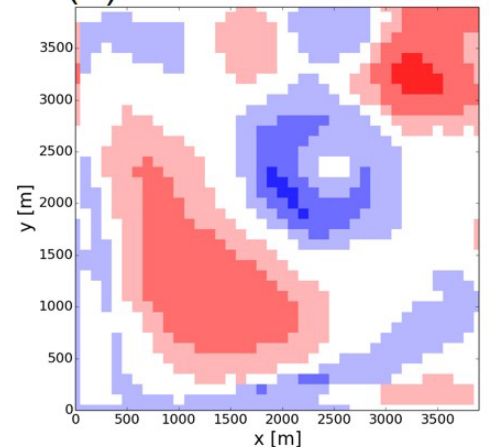

(c)

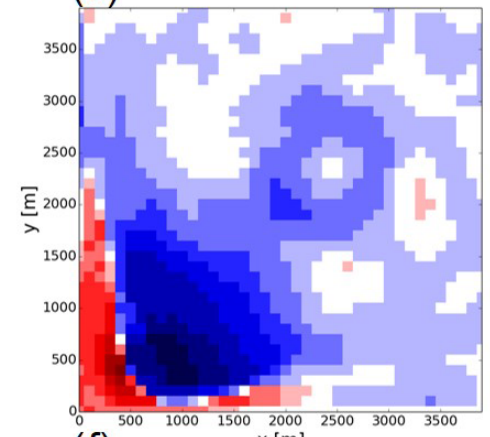

(f)

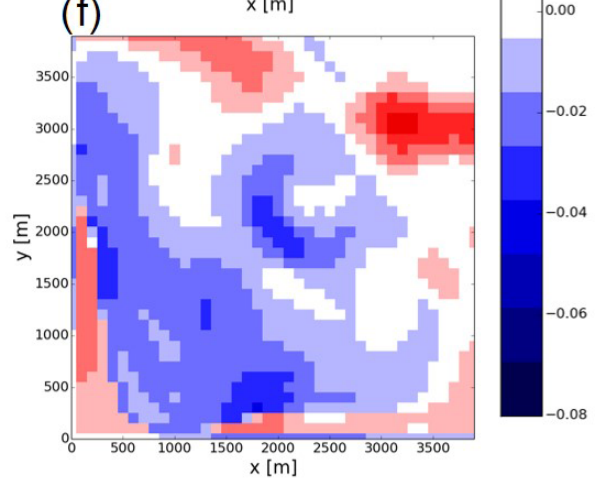

Figure 9. Differences of time-mean soil moisture RMSEs between the DA experiments and the OF_NoDA experiment. (a) OF_DA_obs1, (b) OF_DA_obs9, (c) OF_DA_obs361, (d) noOF_DA_obs1, (e) noOF_DA_obs9, and (f) noOF_DA_obs361.

(a)

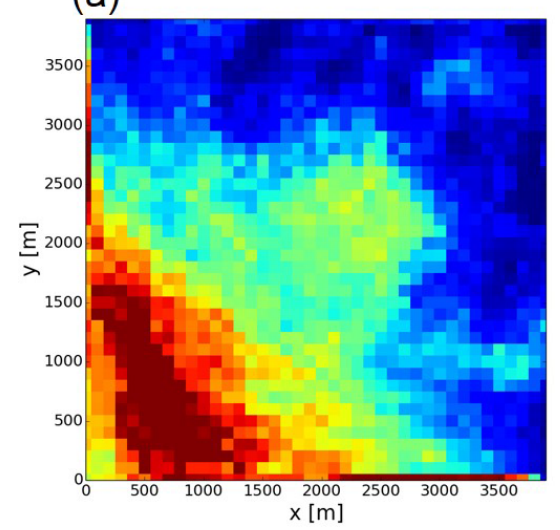

(b)

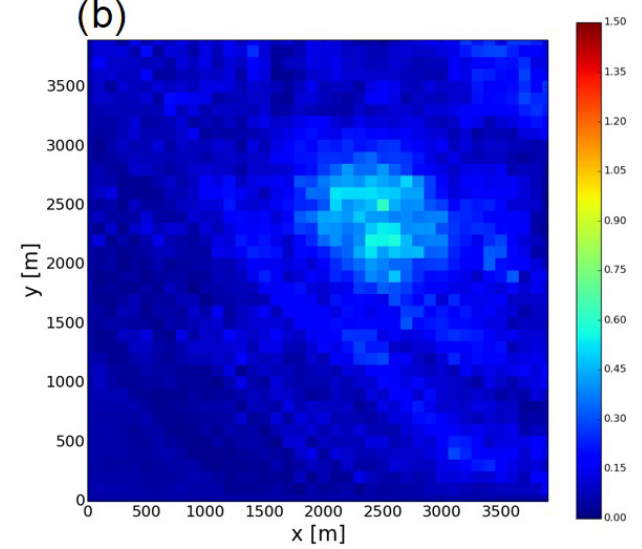

Figure 10. The Kullback-Leibler divergence of ensemble members generated by the (a) OF_NoDA and (b) noOF_NoDA experiments at $t=4(\mathrm{~h})$.

OF configuration does not occur when the topography-driven surface flow is neglected since the ensemble simulation does not generate the non-Gaussian background distribution (Fig. 10b). Although ETKF can significantly improve the simulation skill of the hyperresolution land model in many cases, I found its limitation when it is applied to the problems with the topography-driven surface lateral flows. Figure 10 clearly indicates that this limitation appears only if lateral water flows are explicitly considered.

\section{Discussion}

In this study, I revealed that the hyperresolution integrated surface-subsurface hydrological model gives the unique opportunity to effectively use soil moisture observations to improve the soil moisture simulation in terms of a horizontal propagation of observation information in a model space. I found that the explicit calculation of the topography-driven surface flow has an important role in propagating the infor- 
mation of soil moisture observation horizontally by data assimilation even if there is considerable heterogeneity of meteorological forcing. It is possible that the soil moisture observations in the area where it does not heavily rain can improve the soil moisture simulation in the severe rainfall area.

This potential cannot be brought out in the conventional 1-D LSM, where sub-grid-scale surface runoff is parameterized and the surface flows in one grid do not move to the adjacent grids. I found that neglecting the topography-driven surface flow causes significant bias in the soil moisture simulation, and this bias cannot be completely mitigated by data assimilation especially in the case of a sparse observing network. However, I found that even if the model uses imperfect physics which neglects the interaction between topographydriven surface lateral flows and subsurface soil moisture, assimilating soil moisture observations into the model's 3-D state and parameter space can improve the skill in estimating soil moisture and hydraulic conductivity. This finding implies that the conventional 1-D LSM with full 3-D data assimilation may be a computationally cheap and reasonable choice in some cases, although many land data assimilation systems with the conventional 1-D LSM currently update state variables only in a single model's horizontal grid which is identical to the location of the observation.

The conventional ensemble data assimilation (i.e., ETKF) severely suffers from the non-Gaussian background error PDFs caused by the strongly nonlinear dynamics of the topography-driven surface flow, although it has been widely used by previous studies (e.g., Camporese et al., 2009, 2010; Ridler et al., 2014; Zhang et al., 2015, 2018; Kurtz et al., 2016). The efficiency of ETKF in propagating the information of observations horizontally in the model space is limited in the edge of the area where the topography-driven surface flow reaches. Please note that the low representativeness of the soil moisture observations in the case of the HIGH_K reference shown in Sect. 3.1 is due to the limitation of the Kalman filter in that the error PDFs need to follow the Gaussian distribution to get the optimal estimation, so that the increase in the ensemble size cannot solve this issue. I implemented the data assimilation experiment in the case of the HIGH_K reference with an ensemble size of 500, which is 10 times larger than the original experiments shown in Sect. 3.1, and found no significant improvement of the soil moisture simulation (not shown). Some studies revealed that volumetric soil moisture distributions follow the Gaussian distribution better than pressure head, so that they recommend updating soil moisture as a state variable (e.g., Zhang et al., 2018). However, in this study, I found that volumetric soil moisture distributions have a bimodal structure and do not follow the Gaussian distribution. The limitation of ensemble Kalman filters found in this study does not depend on the updated state variables.

In addition, I found ensemble clustering in which the ensemble members are split into a single outlier and the others (see Figs. S1-S4). The previous studies found that this ensemble clustering is generated by the non-Gaussian PDF (Anderson, 2010; Amezcua et al., 2012). Ensemble clustering shown in the analysis time series also implies that the non-Gaussian PDF plays an important role in the data assimilation of the hyperresolution land model.

The spatially dense soil moisture observations are needed to efficiently constrain state variables at the edge of surface flows. High-resolution soil moisture remote sensing based on satellite active and passive combined microwave observations at the $1 \mathrm{~km}$ spatial resolution (e.g., He et al., 2018) and the assimilation of those data (Lievens et al., 2017) may be important in the era of the hyperresolution land modeling. High-resolution observations of surface-inundated water from satellite imagery with a spatial resolution finer than $100 \mathrm{~m}$ (e.g., Sakamoto et al., 2007; Arnesen et al., 2013) may also be useful. However, the numerical experiment in Sect. 3.2 implies that the dense observing network of surface soil moisture cannot completely remove the negative impact of the non-Gaussian background PDF.

As a possible heuristic approach to avoid the negative impact of the non-Gaussian background PDF, I can omit updating the state variables in the edge of the area where topography-driven surface flow reaches. The numerical experiments clearly indicate that the negative impact of the nonlinear physics and non-Gaussian PDF is found only in the edge of flooding areas, so that it is beneficial to simply omit updating the state variables in this area. It is similar but not conceptually identical to the localization method, in which the spurious correlation sampled by an ensemble is eliminated by spatially restricting the impact of assimilating observation (e.g., Rasmussen et al., 2015; Anderson, 2007; Bishop and Hodyss, 2009).

Reducing the uncertainty in rainfall positively impacts the efficiency of data assimilation since the bifurcation of simulated soil moisture found in Fig. $5 \mathrm{c}$ is originally induced by the uncertainty in rainfall. Although assimilating land hydrological observations to improve the rainfall input has been intensively investigated (e.g., Sawada et al., 2018; Herrnegger et al., 2015; Crow et al., 2011; Vrugt et al., 2008), it has yet to be applied to hyperresolution land models. Please note that the parameters of the lognormal distribution to model the uncertainty in rainfall were specified to make the rainfall PDF similar to the Gaussian distribution. I chose the lognormal distribution in order not to generate negative rainfall values and I intended not to introduce non-Gaussianity into the external forcing. The rainfall input which follows the Gaussian PDF was transformed into the non-Gaussian PDF of the background error by the strongly nonlinear dynamics of the topography-driven surface flow.

To explicitly consider non-Gaussianity and the nonlinear relationship between observed and unobserved variables induced by the topography-driven surface flow, the particle filters may be useful. The particle filter can represent a probability distribution (including non-Gaussian distributions) directly by an ensemble. Particle filters have been intensively 
applied to conventional 1-D LSMs (e.g., Sawada et al., 2015; Qin et al., 2009) and lumped hydrological models (e.g., Yan and Moradkhani, 2016; Vrugt et al., 2013). Although particle filtering in a high-dimensional system suffers from the "curse of dimensionality" (e.g., Snyder et al., 2008), some studies developed the methodology to improve the efficiency of particle filtering (e.g., van Leeuwen, 2009; Poterjoy et al., 2019). The applicability of particle filtering to 3-D hyperresolution land models should be assessed in the future.

Since the synthetic numerical experiments in this paper adopted the simple and minimalistic setting, the findings of this paper may be exaggerated. There are no river channels in the synthetic experiment, so that the skill in simulating river water level and discharge cannot be discussed, which is the major limitation of this study. The simple representation of soil properties is also a limitation of this study. Although the prior uncertainty in rainfall and saturated hydraulic conductivity was arbitrarily chosen in this study, the specification of the prior knowledge is not straightforward in the real-world applications. In future work, the contributions of the topography-driven surface runoff process to the data assimilation of hydrological observations should be quantified in real-world applications. In addition, in the virtual experiment of this paper, I neglected some of the important land processes, such as transpiration, canopy interception, snow, and frozen soil. These processes affect the source term of Eq. (1) in hyperresolution land models (e.g., Shrestha et al., 2014). Since the inclusion of the neglected processes do not change the structure of the original ParFlow, the findings of this study can be robust to the models which include these processes. Although they are generally not primary factors in the propagation of overland flows generated by extreme rainfall, which has a shorter timescale than the neglected processes, those processes should be considered in the future.

The other limitation of this study is that I could not thoroughly evaluate the skill of the ensemble data assimilation in quantifying the uncertainty of its prediction. Following Abbazadeh et al. (2019), I calculated the $95 \%$ exceedance ratio and found that the ensemble forecast was systematically overconfident (not shown). In the synthetic experiments of this study, the number of rainfall events was small, and the timing and magnitude of rainfall were not diversified. Due to this limited amount of data, it is difficult to discuss in depth the accuracy of the quantified uncertainty by data assimilation. While the skill of lumped hydrological models was often evaluated by the probabilistic performance measures such as the $95 \%$ exceedance ratio (e.g., Abbazadeh et al., 2019), the uncertainty quantification of the simulation of hyperresolution land models is in its infancy. How surface lateral flows affect the accuracy of the uncertainty quantification by data assimilation should be investigated using more realistic data.

\section{Conclusions}

The simplified synthetic experiments of this study indicate that topography-driven lateral surface flows induced by heavy rainfalls do matter for data assimilation of hydrological observations into hyperresolution land models. Even if there is extreme heterogeneity of rainfall, the information of soil moisture observations can be propagated horizontally in the model space and the soil moisture simulation can be improved by the ensemble Kalman filter. However, the nonlinear dynamics of the topography-driven surface flow induces the non-Gaussianity of the model error, which harms the efficiency of data assimilation of soil moisture observations. It is difficult to efficiently constrain model states at the edge of the area where the topography-driven surface flow reaches by linear-Gaussian filters, which brings the new challenge in land data assimilation for hyperresolution land models. Future work will focus on the real-world applications using intense in situ soil moisture observation networks and/or highresolution satellite soil moisture observations.

Code and data availability. All data used in this paper are stored in the repository of the University of Tokyo for 5 years and are available upon request to the author. The ETKF code used in this study can be found at https://github.com/takemasa-miyoshi/letkf (last access: 31 July 2020) (Miyoshi, 2020).

Supplement. The supplement related to this article is available online at: https://doi.org/10.5194/hess-24-3881-2020-supplement.

Competing interests. The authors declare that they have no conflict of interest.

Acknowledgements. This study was supported by JSPS KAKENHI grants JP17K18352 and JP18H03800. I thank two anonymous reviewers for their constructive comments.

Financial support. This research has been supported by the Japan Society for the Promotion of Science (grant nos. JP17K18352 and JP18H03800).

Review statement. This paper was edited by Alberto Guadagnini and reviewed by two anonymous referees. 


\section{References}

Abbaszadeh, P., Moradkhani, H., and Daescu, D. N.: The Quest for Model Uncertainty Quantification: A Hybrid Ensemble and Variational Data Assimilation Framework, Water Resour. Res., 55, 2407-2431, https://doi.org/10.1029/2018WR023629, 2019.

Ait-El-Fquih, B., El Gharamti, M., and Hoteit, I.: A Bayesian consistent dual ensemble Kalman filter for state-parameter estimation in subsurface hydrology, Hydrol. Earth Syst. Sc., 20, 32893307, https://doi.org/10.5194/hess-20-3289-2016, 2016.

Arnesen, A. S., Silva, T. S. F., Hess, L. L., Novo, E. M. L. M., Rudorff, C. M., Chapman, B. D., and McDonald, K. C.: Monitoring flood extent in the lower Amazon River floodplain using ALOS/PALSAR ScanSAR images, Remote Sens. Environ., 130, 51-61, https://doi.org/10.1016/j.rse.2012.10.035, 2013.

Amezcua, J., Ide, K., Bishop, C. H., and Kalnay, E.: Ensemble clustering in deterministic ensemble Kalman filters, Tellus A, 64, 112, https://doi.org/10.3402/tellusa.v64i0.18039, 2012.

Anderson, J. L.: Exploring the need for localization in ensemble data assimilation using a hierarchical ensemble filter, Physica D, 230, 99-111, https://doi.org/10.1016/j.physd.2006.02.011, 2007.

Anderson, J. L.: A non-Gaussian ensemble filter update for data assimilation, Mon. Weather Rev., 138, 4186-4198, https://doi.org/10.1175/2010MWR3253.1, 2010.

Bandara, R., Walker, J. P., and Rüdiger, C.: Towards soil property retrieval from space: Proof of concept using in situ observations, J. Hydrol., 512, 27-38, https://doi.org/10.1016/j.jhydrol.2014.02.031, 2014.

Bandara, R., Walker, J. P., Rüdiger, C., and Merlin, O.: Towards soil property retrieval from space: An application with disaggregated satellite observations, J. Hydrol., 522, 582-593, https://doi.org/10.1016/j.jhydrol.2015.01.018, 2015.

Beven, K.: On subsurface stormflow: an analysis of response times, Hydrolog. Sci. J., 27, 505-521, https://doi.org/10.1080/02626668209491129, 1982.

Bishop, C. H. and Hodyss, D.: Ensemble covariances adaptively localized with ECO-RAP. Part 1: Tests on simple error models, Tellus A, 61, 84-96, https://doi.org/10.1111/j.16000870.2008.00371.x, 2009.

Bishop, C. H., Etherton, B. J., and Majumdar, S. J.: Adaptive Sampling with the Ensemble Transform Kalman Filter. Part I: Theoretical Aspects, Mon. Weather Rev., 129, 420-436, https://doi.org/10.1175/15200493(2001)129<0420:ASWTET>2.0.CO;2, 2001.

Camporese, M., Paniconi, C., Putti, M., and Salandin, P.: Ensemble Kalman filter data assimilation for a process-based catchment scale model of surface and subsurface flow, Water Resour. Res., 45, 1-14, https://doi.org/10.1029/2008WR007031, 2009.

Camporese, M., Paniconi, C., Putti, M., and Orlandini, S.: Surfacesubsurface flow modeling with path-based runoff routing, boundary condition-based coupling, and assimilation of multisource observation data, Water Resour. Res., 46, W02512, https://doi.org/10.1029/2008WR007536, 2010.

Crow, W. T., Van Den Berg, M. J., Huffman, G. J., and Pellarin, T.: Correcting rainfall using satellite-based surface soil moisture retrievals: The Soil Moisture Analysis Rainfall Tool (SMART). Water Resour. Res., 47, 1-15, https://doi.org/10.1029/2011WR010576, 2011.

Dorigo, W., Wagner, W., Albergel, C., Albrecht, F., Balsamo, G., Brocca, L., Chung, D., Ertl, M., Forkel, M., Gruber, A., Haas, E.,
Hamer, P. D., Hirschi, M., Ikonen, J., de Jeu, R., Kidd, R., Lahoz, W., Liu, Y. Y., Miralles, D., Mistelbauer, T., Nicolai-Shaw, N., Parinussa, R., Pratola, C., Reimer, C., van der Schalie, R., Seneviratne, S. I., Smolander, T., and Lecomte, P.: ESA CCI Soil Moisture for improved Earth system understanding: State-of-the art and future directions, Remote Sens. Environ., 203, 185-215, https://doi.org/10.1016/j.rse.2017.07.001, 2017.

Duc, L. and Saito, K.: Verification in the presence of observation errors: Bayesian point of view, Q. J. Roy. Meteorol. Soc., 144, 1063-1090, https://doi.org/10.1002/qj.3275, 2018.

Fang, Y. L. R., Leung, Z. Duan, M. S., Wigmosta, R. M., Maxwell, J. Q., Chambers, J. Q., and Tomasella, J.: Influence of landscape heterogeneity on water available to tropical forests in an Amazonian catchment and implications for modeling drought response, J. Geophys. Res.-Atmos., 122, 8410-8426, https://doi.org/10.1002/2017JD027066, 2017.

Ghanbarian-Alavijeh, B., Liaghat, A., Huang, G., H., and van Genuchten, M. T.: Estimation of the van Genuchten soil water retention properties from soil textural data, Pedosphere, 20, 456-465, 2010.

Han, X., Franssen, H.-J. H., Montzka, C., and Vereecken, H.: Soil moisture and soil properties estimation in the Community Land Model with synthetic brightness temperature observations, Water Resour. Res., 50, 6081-6105, https://doi.org/10.1002/2013WR014586, 2014.

He, L., Hong, Y., Wu, X., Ye, N., Walker, J. P., and Chen, X.: Investigation of SMAP Active-Passive Downscaling Algorithms Using Combined Sentinel-1 SAR and SMAP Radiometer Data, IEEE T. Geosci. Remote, 56, 4906-4918, https://doi.org/10.1109/TGRS.2018.2842153, 2018.

Hendricks Franssen, H. J. and Kinzelbach, W.: Real-time groundwater flow modeling with the Ensemble Kalman Filter: Joint estimation of states and parameters and the filter inbreeding problem, Water Resour. Res., 44, 1-21, https://doi.org/10.1029/2007WR006505, 2008.

Herrnegger, M., Nachtnebel, H. P., and Schulz, K.: From runoff to rainfall: inverse rainfall-runoff modelling in a high temporal resolution, Hydrol. Earth Syst. Sci., 19, 4619-4639, https://doi.org/10.5194/hess-19-4619-2015, 2015.

Houborg, R., Rodell, M., Li, B., Reichle, R., and Zaitchik, B. F.: Drought indicators based on model-assimilated Gravity Recovery and Climate Experiment (GRACE) terrestrial water storage observations, Water Resour. Res., 48, W07525, https://doi.org/10.1029/2011WR011291, 2012.

Houtekamer, P. L. and Zhang, F.: Review of the Ensemble Kalman Filter for Atmospheric Data Assimilation, Mon. Weather Rev., 144, 4489-4532, https://doi.org/10.1175/MWRD-15-0440.1, 2016.

Hunt, B. R., Kostelich, E. J., and Szunyogh, I.: Efficient data assimilation for spatiotemporal chaos: A local ensemble transform Kalman filter, Physica D, 230, 112-126, https://doi.org/10.1016/j.physd.2006.11.008, 2007.

Ji, P., Yuan, X., and Liang, X. Z.: Do Lateral Flows Matter for the Hyperresolution Land Surface Modeling?, J. Geophys. Res.-Atmos., 583, 12077-12092, https://doi.org/10.1002/2017JD027366, 2017.

Keune, J. F., Gasper, K., Goergen, A., Hense, P., Shrestha, M., Sulis, M., and Kollet, S.: Studying the influence of groundwater representations on land surface-atmosphere feedbacks during the Eu- 
ropean heat wave in 2003, J. Geophys. Res.-Atmos., 121, 1330113325, https://doi.org/10.1002/2016JD025426, 2016.

Kollet, S. J. and Maxwell, R. M.: Integrated surface-groundwater flow modeling: A free-surface overland flow boundary condition in a parallel groundwater flow model, Adv. Water Resour., 29, 945-958, https://doi.org/10.1016/j.advwatres.2005.08.006, 2006.

Kondo, K. and Miyoshi, T.: Non-Gaussian statistics in global atmospheric dynamics: a study with a 10240-member ensemble Kalman filter using an intermediate atmospheric general circulation model, Nonlin. Process Geophys., 26, 211-225, https://doi.org/10.5194/npg-26-211-2019, 2019.

Kullback, S. and Leibler, R. A.: On information and sufficiency, Ann. Math. Stat., 22, 79-86, 1951.

Kumar, S. V., Reichle, R. H., Koster, R. D., Crow, W. T., and PetersLidard, C. D.: Role of Subsurface Physics in the Assimilation of Surface Soil Moisture Observations, J. Hydrometeorol., 10, 1534-1547, https://doi.org/10.1175/2009JHM1134.1, 2009.

Kurtz, W., He, G., Kollet, S. J., Maxwell, R. M., Vereecken, H., and Franssen, H. J. H.: TerrSysMP-PDAF (version 1.0): A modular high-performance data assimilation framework for an integrated land surface-subsurface model, Geosci. Model Dev., 9, 13411360, https://doi.org/10.5194/gmd-9-1341-2016, 2016.

Lawrence, D. M., Oleson, K. O., Flanner, M. G., Thornton, P. E., Swenson, S. C., Lawrence, P. J., Zeng, X., Yang, Z.-L., Levis, S., Sakaguchi, K., Bonan, G. B., and Slater, A. G.: Parameterization improvements and functional and structural advances in Version 4 of the Community Land Model, J. Adv. Model. Earth Syst., 3, 1-27, https://doi.org/10.1029/2011MS000045, 2011.

Li, B., Rodell, M., Zaitchik, B. F., Reichle, R. H., Koster, R. D., and van Dam, T. M.: Assimilation of GRACE terrestrial water storage into a land surface model: Evaluation and potential value for drought monitoring in western and central Europe, J. Hydrol., 446-447, 103-115, https://doi.org/10.1016/j.jhydrol.2012.04.035, 2012.

Lievens, H., Reichle, R. H., Liu, Q., De Lannoy, G. J. M., Dunbar, R. S., Kim, S. B., Das, N. N., Cosh, M., Walker, J. P., and Wagner, W.: Joint Sentinel-1 and SMAP data assimilation to improve soil moisture estimates, Geophys. Res. Lett., 44, 61456153, https://doi.org/10.1002/2017GL073904, 2017.

Martens, B., Miralles, D. G., Lievens, H., Schalie, R. Van Der, and De Jeu, R. A. M.: GLEAM v3: satellite-based land evaporation and root-zone soil moisture, Geosci. Model Dev., 10, 1903-1925, https://doi.org/10.5194/gmd-10-1903-2017, 2017.

Maxwell, R. M. and Condon, L. E.: Connections between groundwater flow and transpiration partitioning, Science, 353, 377-380, https://doi.org/10.1126/science.aaf7891, 2016.

Maxwell, R. M. and Kollet, S. J.: Interdependence of groundwater dynamics and land-energy feedbacks under climate change, Nat. Geosci., 1, 665-669, https://doi.org/10.1038/ngeo315, 2008.

Maxwell, R. M. and Miller, N. L.: Development of a Coupled Land Surface and Groundwater Model, J. Hydrometeorol., 6, 233-247, https://doi.org/10.1175/JHM422.1, 2005.

Maxwell, R. M., Lundquist, J. K., Mirocha, J. D., Smith, S. G., Woodward, C. S., and Tompson, A. F. B.: Development of a Coupled Groundwater-Atmosphere Model, Mon. Weather Rev., 139, 96-116, https://doi.org/10.1175/2010MWR3392.1, 2011.

Maxwell, R. M., Condon, L. E., and Kollet, S. J.: A high-resolution simulation of groundwater and surface water over most of the continental US with the integrated hydrologic model ParFlow v3, Geosci. Model Dev., 8, 923-937, https://doi.org/10.5194/gmd-8923-2015, 2015.

Miyoshi, T.: letkf, available at: https://github.com/ takemasa-miyoshi/letkf, last access: 31 July 2020.

Moradkhani, H., Hsu, K. L., Gupta, H., and Sorooshian, S.: Uncertainty assessment of hydrologic model states and parameters: Sequential data assimilation using the particle filter, Water Resour. Res., 41, 1-17, https://doi.org/10.1029/2004WR003604, 2005.

Nerger, L. and Hiller, W.: Software for ensemble-based data assimilation systems - implementation strategies and scalability, Comput. Geosci., 55, 110-118, https://doi.org/10.1016/j.cageo.2012.03.026, 2013.

Niu, G. Y., Paniconi, C., Troch, P. A., Scott, R. L., Durcik, M., Zeng, X., and Goodrich, D. C.: An integrated modelling framework of catchment-scale ecohydrological processes: 1 . Model description and tests over an energy-limited watershed, Ecohydrology, 7, 427-439, https://doi.org/10.1002/eco.1362, 2014.

Paloscia, S, Pettinato, S., Santi, E., Notarnicola, C., Pasolli, L., and Reppucci, A.: Soil moisture mapping using Sentinel-1 images: Algorithm and preliminary validation, Remote Sens. Environ., 134, 234-248, https://doi.org/10.1016/j.rse.2013.02.027, 2013.

Pokhrel, P. and Gupta, H. V.: On the use of spatial regularization strategies to improve calibration of distributed watershed models, Water Resour. Res., 46, 1-17, https://doi.org/10.1029/2009WR008066, 2010.

Poterjoy, J., Wicker, L., and Buehner, M.: Progress toward the application of a localized particle filter for numerical weather prediction, Mon. Weather Rev., 147, 1107-1126, https://doi.org/10.1175/MWR-D-17-0344.1, 2019.

Qin, J., Liang, S., Yang, K., Kaihotsu, I., Liu, R., and Koike, T.: Simultaneous estimation of both soil moisture and model parameters using particle filtering method through the assimilation of microwave signal, J. Geophys. Res., 114, 1-13, https://doi.org/10.1029/2008JD011358, 2009.

Rasmussen, J., Madsen, H., Jensen, K. H., and Refsgaard, J. C.: Data assimilation in integrated hydrological modeling using ensemble Kalman filtering: evaluating the effect of ensemble size and localization on filter performance, Hydrol. Earth Syst Sci., 19, 2999-3013, https://doi.org/10.5194/hess-19-2999-2015, 2015.

Ridler, M.-E., H. Madsen, S. Stisen,, S. Bircher, and Fensholt, R.: Assimilation of SMOS-derived soil moisture in a fully integrated hydrological and soil-vegetation-atmosphere transfer model in Western Denmark, Water Resour. Res., 50, 8962-8981, https://doi.org/10.1002/2014WR015392, 2014.

Sakamoto, T., Nguyen, N. V., Kotera, A., Ohno, H., Ishitsuka, N., and Yokozawa, M.: Detecting temporal changes in the extent of annual flooding within the Cambodia and the Vietnamese Mekong Delta from MODIS timeseries imagery, Remote Sens. Environ., 109, 295-313, https://doi.org/10.1016/j.rse.2007.01.011, 2007.

Sawada, Y. and Koike, T.: Simultaneous estimation of both hydrological and ecological parameters in an eco-hydrological model by assimilating microwave signal, J. Geophys. Res.-Atmos., 119, 8839-8857, https://doi.org/10.1002/2014JD021536, 2014.

Sawada, Y., Koike, T., and Walker, J. P.: A land data assimilation system for simultaneous simulation of soil moisture and veg- 
etation dynamics, J. Geophys. Res.-Atmos., 120, 5910-5930, https://doi.org/10.1002/2014JD022895, 2015.

Sawada, Y., Nakaegawa, T., and Miyoshi, T.: Hydrometeorology as an inversion problem: Can river discharge observations improve the atmosphere by ensemble data assimilation?, J. Geophys. Res.-Atmos., 123, 848-860, https://doi.org/10.1002/2017JD027531, 2018.

Sellers, P. J., Randall, D. A., Collatz, G. J., Berry, J. A., Field, C. B., Dazlich, D. A., Zhang, C., Collelo, G. D., and Bounoua, L.: A revised land surface parameterization (SiB2) for atmospheric GCMs. Part I: Model formulation, J. Climate, https://doi.org/10.1175/1520-0442(1996)009<0676:ARLSPF>2.0.CO;2, 1996.

Shrestha, P., Sulis, M., Masbou, M., Kollet, S., and Simmer, C.: A Scale-Consistent Terrestrial Systems Modeling Platform Based on COSMO, CLM, and ParFlow, Mon. Weather Rev., 142, 34663483, https://doi.org/10.1175/MWR-D-14-00029.1, 2014.

Snyder, C., Bengtsson, T., Bickel, P., and Anderson, J.: Obstacles to High-Dimensional Particle Filtering, Mon. Weather Rev., 136, 4629-4640, https://doi.org/10.1175/2008MWR2529.1, 2008.

Tian, W., Li, X., Cheng, G. D., Wang, X. S., and Hu, B. X.: Coupling a groundwater model with a land surface model to improve water and energy cycle simulation, Hydrol. Earth Syst. Sci., 16, 47074723, https://doi.org/10.5194/hess-16-4707-2012, 2012.

Van Genuchten, M. T.: A closed-form equation for predicting the hydraulic conductivity of unsaturated soils, Soil Sci. Soc. Am. J., 44, 892-898, 1980.

Van Leeuwen, P. J.: Particle Filtering in Geophysical Systems, Mon. Weather Rev., 137, 4089-4114, https://doi.org/10.1175/2009MWR2835.1, 2009.

Verbeeck, H., Peylin, P., Bacour, C., Bonal, D., Steppe, K., and Ciais, P.: Fluxes in Amazon forests: Fusion of eddy covariance data and the ORCHIDEE model, J. Geophys. Res., 116, 1-19, https://doi.org/.10.1029/2010JG001544, 2011.

Vrugt, J. A., ter Braak, C. J. F., Clark, M. P., Hyman, J. M., and Robinson, B. A.: Treatment of input uncertainty in hydrologic modeling: Doing hydrology backward with Markov chain Monte Carlo simulation, Water Resour. Res., 44, 1-15, https://doi.org/10.1029/2007WR006720, 2008.

Vrugt, J. A., ter Braak, C. J. F., Diks, C. G. H., and Schoups, G.: Hydrologic data assimilation using particle Markov chain Monte Carlo simulation: Theory, concepts and applications, Adv. Water Resour., 51, 457-478, https://doi.org/10.1016/j.advwatres.2012.04.002, 2013.
Williams, J. L. and Maxwell, R. M.: Propagating Subsurface Uncertainty to the Atmosphere Using Fully Coupled Stochastic Simulations, J. Hydrometeorol., 12, 690-701, https://doi.org/10.1175/2011JHM1363.1, 2011.

Wood, E. F., Roundy, J. K., Troy, T. J., van Beek, L. P. H., Bierkens, M. F. P., Blyth, E., de Roo, A., Döll, P., Ek, M., Famiglietti, J., Gochis, D., van de Giesen, N., Houser, P., Jaffé, P. R., Kollet, S., Lehner, B., Lettenmaier, D. P., Peters-Lidard, C., Sivapalan, M., Sheffield, J., Wade, A., and Whitehead, P.: Hyperresolution global land surface modeling: Meeting a grand challenge for monitoring Earth's terrestrial water, Water Resour. Res., 47, W5301, https://doi.org/10.1029/2010WR010090, 2011.

Yan, H. and Moradkhani, H.: Combined assimilation of streamflow and satellite soil moisture with the particle filter and geostatistical modeling, Adv. Water Resour., 94, 364-378, https://doi.org/10.1016/j.advwatres.2016.06.002, 2016.

Yang, K., Watanabe, T., Koike, T., Li, X., Fujii, H., Tamagawa, K., and Ishikawa, H.: Auto-calibration System Developed to Assimilate AMSR-E Data into a Land Surface Model for Estimating Soil Moisture and the Surface Energy Budget, J. Meteorol. Soc. Jpn., 85A, 229-242, https://doi.org/10.2151/jmsj.85A.229, 2007.

Yang, K., Koike, T., Kaihotsu, I., and Qin, J.: Validation of a DualPass Microwave Land Data Assimilation System for Estimating Surface Soil Moisture in Semiarid Regions, J. Hydrometeorol., 10, 780-793, https://doi.org/10.1175/2008JHM1065.1, 2009.

Zhang, D., Madsen, H., Ridler, M. E., Refsgaard, J. C., and Jensen, K. H.: Impact of uncertainty description on assimilating hydraulic head in the MIKE SHE distributed hydrological model, Adv. Water Resour., 86, 400-413, https://doi.org/10.1016/j.advwatres.2015.07.018, 2015.

Zhang, F., Snyder, C., and Sun, J.: Impacts of Initial Estimate and Observation Availability on Convective-Scale Data Assimilation with an Ensemble Kalman Filter, Mon. Weather Rev., 132, 1238-1253, https://doi.org/10.1175/15200493(2004)132<1238:IOIEAO>2.0.CO;2, 2004.

Zhang, H., Kurtz, W., Kollet, S., Vereecken, H., and Franssen, H. J. H.: Comparison of different assimilation methodologies of groundwater levels to improve predictions of root zone soil moisture with an integrated terrestrial system model, Adv. Water Resour., 111, 224-238, https://doi.org/10.1016/j.advwatres.2017.11.003, 2018. 